\title{
APP-C31 is an intracellular promoter of amyloid- $\beta$ aggregation and toxicity
}

\author{
Eunju Nam ${ }^{1}$, Jiyong Park ${ }^{1,2}$, Yuxi Lin ${ }^{3}$, Hyunsu Do ${ }^{4}$, Jiyeon Han ${ }^{1}$, Jinju Han ${ }^{4 *}$, Young-Ho \\ $\mathrm{Lee}^{3,5,6,7 *}$, Mu-Hyun Baik ${ }^{1,2 *}$ and Mi Hee Lim ${ }^{1 *}$
}

${ }^{1}$ Department of Chemistry, Korea Advanced Institute of Science and Technology (KAIST), Daejeon 34141, Republic of Korea

${ }^{2}$ Center for Catalytic Hydrocarbon Functionalizations, Institute for Basic Science (IBS), Daejeon 34141, Republic of Korea

${ }^{3}$ Research Center of Bioconvergence Analysis, Korea Basic Science Institute (KBSI), Ochang, Chungbuk 28119, Republic of Korea

${ }^{4}$ Graduate School of Medical Science and Engineering, KAIST, Daejeon 34141, Republic of Korea

${ }^{5}$ Bio-Analytical Science, University of Science and Technology (UST), Daejeon 34113, Republic of Korea

${ }^{6}$ Graduate School of Analytical Science and Technology, Chungnam National University, Daejeon 34134, Republic of Korea

${ }^{7}$ Research Headquarters, Korea Brain Research Institute (KBRI), Daegu 41068, Republic of Korea

*To whom correspondence should be addressed: miheelim@kaist.ac.kr, mbaik2805@kaist.ac.kr, mr0505@kbsi.re.kr, and jinjuhan@kaist.ac.kr 


\begin{abstract}
Intracellular $C$-terminal cleavage of the amyloid precursor protein (APP) is elevated in the brain of Alzheimer's disease (AD). Emerging evidence proposes a pathological relationship between the production of a $C$-terminal APP fragment, called APP-C31, and the toxicity induced by amyloid- $\beta(A \beta)$ that is a major contributor towards $A D$; however, the interaction between the two peptides and the consequent impact of APP-C31 on A $\beta$-related toxicity were unknown thus far. Here we report the discovery that APP-C31 facilitates the aggregation of A $\beta$ and aggravates its toxicity at the intracellular level, with escalating neurodegeneration. APP-C31 forms a heterodimer with $A \beta$ through the contacts onto the $N$-terminal and self-recognition regions of $A \beta$ and induces its conformational transition accelerating amyloid fibrillization. APP-C31 promotes the perinuclear and intranuclear deposition of enlarged $A \beta$ aggregates and, consequently, damages the nucleus leading to apoptosis. $A \beta$-induced degeneration of neurites in human neurons is also intensified by APP-C31. Our studies demonstrate a new function of APP-C31 as an intracellular factor of the proteopathy found in AD.
\end{abstract}


Proteolysis of the amyloid precursor protein (APP) is associated with the pathology of Alzheimer's disease (AD). As a type-I transmembrane protein, APP is localized in cell surfaces or membranes of organelles ${ }^{1,2}$. Cleavage of APP by proteolytic enzymes such as $\alpha-, \beta-$, and $\gamma$-secretases releases various fragments that participate in neurotrophic activities, synaptic plasticity, and intracellular signaling ${ }^{1}$. Amyloid- $\beta(A \beta)$ peptides with 38-43 amino acid residues are generated via the sequential cleavage of APP by $\beta$ - and $\gamma$-secretases, ${ }^{1,3}$ as illustrated in Fig. 1a. Intrinsically disordered $A \beta$ peptides self-assemble into oligomers and fibrils that trigger neurodegeneration observed in $A D^{1-4}$. As the primary constituent of senile plaques, $A \beta$ peptides were first found outside the neuron ${ }^{2,3}$. Extracellular $A \beta$ aggregates are thought to promote synaptic loss and memory impairment ${ }^{2,4}$. Curiously, recent studies supported the production of intracellular $A \beta$ by cellular secretory pathways with its pathological relevance towards $A D^{2}$. In vivo studies have identified that the intraneuronal accumulation of $A \beta$ aggregates could cause cognitive deficits prior to forming senile plaques ${ }^{2,5}$. Thus, $A \beta$ inside the cell may be a source of neurotoxicity.

As depicted in Fig. 1a, a cytoplasmic peptide carrying 31 amino acid residues denoted APPC31 (APP ${ }_{665-695}$ ) is produced upon cleavage of the $C$-terminal region of APP by caspases ${ }^{1,6-8}$. In $A D$-affected brains, the levels of activated caspases are elevated and give rise to caspasemediated APP fragments ${ }^{6-8}$. Like A $\beta$, APP-C31 contributes to neuronal toxicity leading to apoptosis and synaptic depression ${ }^{7,9-13}$. Mutation of APP from Asp664 to Ala that prevents the production of APP-C31 could diminish synaptic loss and neurodegeneration in AD transgenic mice ${ }^{11,12}$. Thus, these findings imply that the amount of intracellular APP-C31 is augmented and, consequently, neurotoxicity is enhanced when $A D$ develops. Recently, the co-localization of the $C$-terminal region of APP with $A \beta$ was observed in intraneuronal perinuclear compartments and multivesicular bodies in the brains of $A D$ transgenic mice ${ }^{14,15}$. Moreover, studies with the $C$ terminal truncated APP, APP $_{1-664}$, and mutant APP(Asp664Ala) suggested that $A \beta$ could activate caspases that induce the $C$-terminal cleavage of APP generating APP-C $31^{11-13}$. Despite these indications, the mechanism of how APP-C31 is involved in the pathology driven by A $\beta$ is not known to date.

We questioned whether APP-C31 can directly bind to $A \beta$ and alter the aggregation and toxicity profiles of $A \beta$. Thus, binding of APP-C31 to $A \beta$ at the molecular level of details and its influence on the aggregation of $A \beta$ were evaluated. In addition, we determined the effects of APP. C31 on modifying the aggregation and toxicity of intracellular $A \beta$ through the live-cell investigations employing the microinjection methods. Moreover, the impact of $A \beta$ incubated with APP-C31 on human neuronal growth was probed. Overall, our work substantiates that an 
intracellular $C$-terminal fragment, APP-C31, can provoke the aggregation behaviors and toxicity of $A \beta$ via direct interactions between the two peptides, which illuminates a new role of APP-C31 as an intracellular factor in the pathology of AD.

a Amyloid precursor protein (APP) Outer membrane

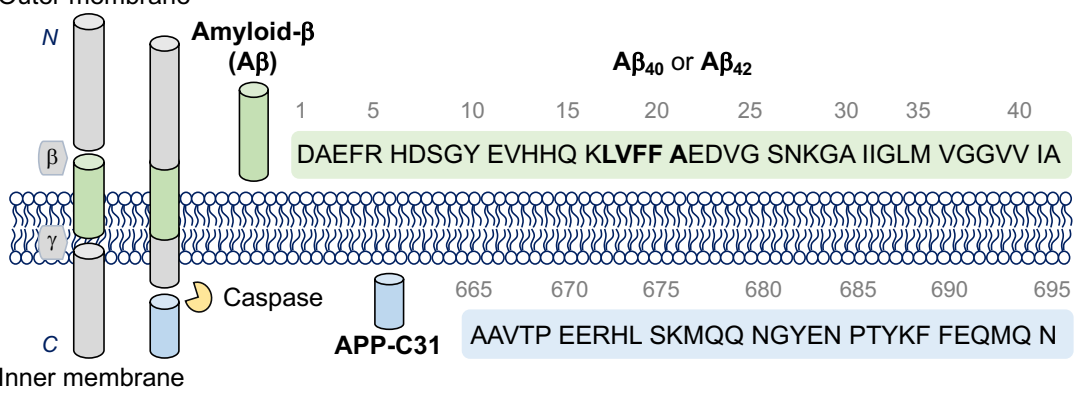

b

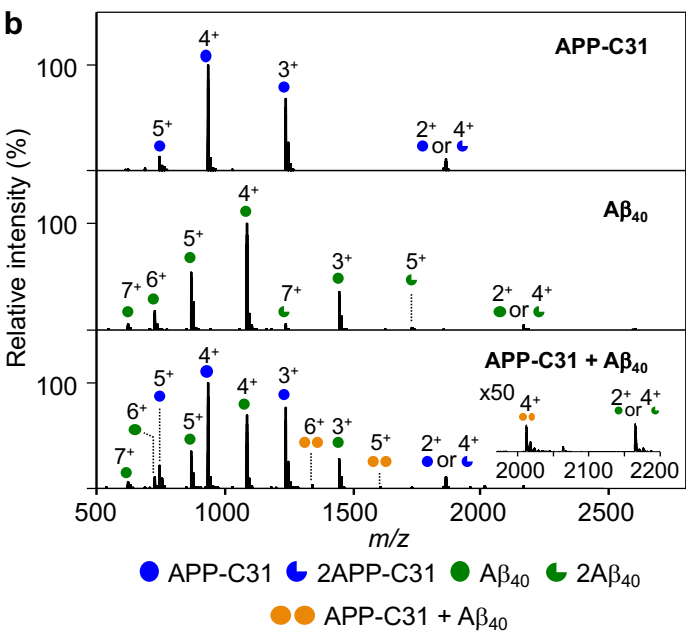

$\beta$ B-Secretase $\gamma \gamma$-Secretase

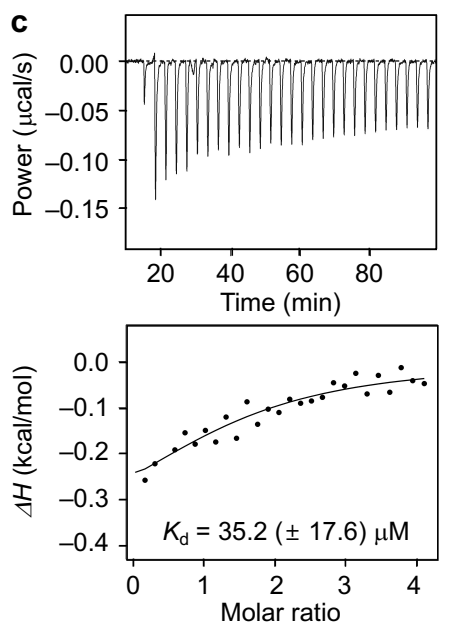

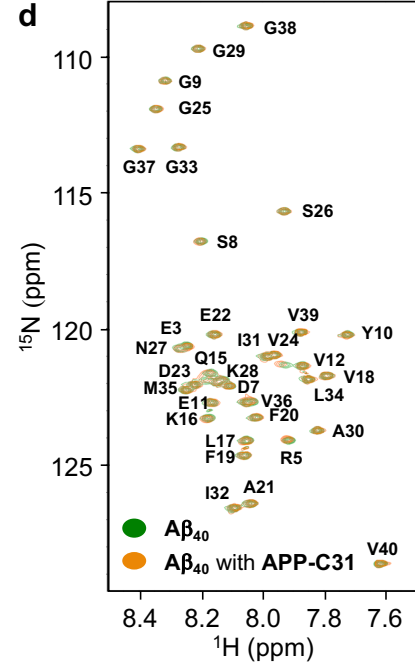

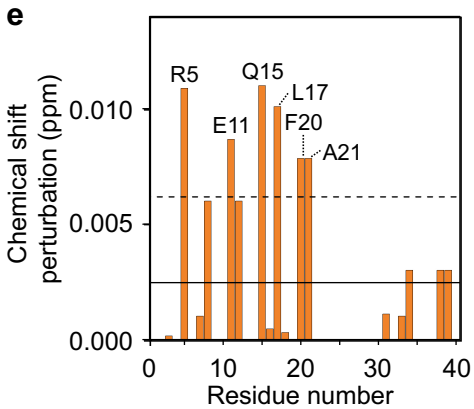

Fig. 1 | APP-C31, A $\beta$, and their direct interactions. a, Amino acid sequences of APP-C31 (APP $665-695), A \beta_{40}$, and $A \beta_{42}$ that are generated from the proteolytic cleavage of $A P P$. The selfrecognition site of $A \beta$ is highlighted in bold. $\mathbf{b}, \mathrm{ESI}-\mathrm{MS}$ spectra of APP-C31, A $\beta_{40}$, and APP-C31 incubated with $A \beta_{40}$. Charge states are marked in the MS spectra. Conditions: [APP-C31] $=100$ $\mu \mathrm{M} ;\left[\mathrm{A} \beta_{40}\right]=100 \mu \mathrm{M} ; 20 \mathrm{mM}$ ammonium acetate, $\mathrm{pH}$ 7.3; $37^{\circ} \mathrm{C} ; 2 \mathrm{~h}$ incubation; no agitation; 10fold diluted samples were injected to the mass spectrometer. c, ITC thermogram (upper panel) and binding isotherm (lower panel) obtained upon titration of APP-C31 to A $\beta_{40}$. Conditions: [A $\beta_{40}$ ] $=30 \mu \mathrm{M} ;$ [APP-C31] = $600 \mu \mathrm{M} ; 20 \mathrm{mM}$ HEPES, pH 7.4; $10{ }^{\circ} \mathrm{C}$. d,e, $2 \mathrm{D}{ }^{1} \mathrm{H}-{ }^{15} \mathrm{~N}$ HSQC spectra $(900 \mathrm{MHz})$ and CSPs of ${ }^{15} \mathrm{~N}$-labeled $\mathrm{A} \beta_{40}$ monomer by treatment of APP-C31. The average of CSPs and the average + one standard deviation are indicated with solid and dashed lines, respectively. Conditions: $\left[{ }^{15} \mathrm{~N}\right.$-labeled $\left.\mathrm{A} \beta_{40}\right]=40 \mu \mathrm{M}$; $[$ APP-C31] $=200 \mu \mathrm{M} ; 20 \mathrm{mM}$ HEPES, pH $7.4 ; 5^{\circ} \mathrm{C}$. 


\section{Results}

Direct binding of APP-C31 to A $\beta$. The molecular-level interaction between APP-C31 and A $\beta$ was first monitored by electrospray ionization-mass spectrometry (ESI-MS), a soft ionization method used in the characterization of protein complexes ${ }^{16}$. A $\beta_{40}$ was used for binding studies because it is a major isoform of $A \beta$ found in $A D$-affected brains and is less aggregation-prone than $A \beta_{42}{ }^{3}$. As shown in Fig. $1 b$, new peaks were observed upon incubation of APP-C31 with $A \beta_{40}$ at 1342, 1610, and $2012 \mathrm{~m} / \mathrm{z}$ that correspond to the complex between APP-C31 and A $\beta_{40}$ with +6, +5 , and +4 charge states, respectively. Furthermore, the molecular binding of APP-C31 with A $\beta_{40}$ was thermodynamically analyzed by isothermal titration calorimetry (ITC). When APP-C31 was titrated into the solution of $A \beta_{40}$, the reaction was spontaneous and exergonic with $\Delta G=-5.8( \pm$ $0.3) \mathrm{kcal} / \mathrm{mol}$ and slightly exothermic at $\Delta H=-0.4( \pm 0.2) \mathrm{kcal} / \mathrm{mol}$, as shown in Fig. 1c. The $T \Delta S$ term was found to be $5.4( \pm 0.4) \mathrm{kcal} / \mathrm{mol}$. The binding affinity of APP-C31 for A $\beta_{40}$ was measured to be $35.2( \pm 17.6) \mu \mathrm{M}$, indicating the relatively weak binding between the two peptides according to previously reported $K_{d}$ values for protein-protein interactions ${ }^{17}$. These thermodynamic properties are curious on first sight, as a reaction in which two particles associate to form a single species is expected to be entropically disfavored. Specifically, it is the translational entropy associated with each particle amounting to roughly $10 \mathrm{kcal} / \mathrm{mol}$ at room temperature that disfavors associative processes reducing the number of free particles ${ }^{18}$. A minor but relevant feature is the loss of structural flexibility upon aggregation, which also reduces the conformational entropy. The increase in entropy observed here is likely due to the release of water molecules that were tightly bound to the protein surfaces and become free water molecules as the two peptides form an association complex.

Direct binding of APP-C31 to A $\beta$ in solution was supported by two dimensional (2D) ${ }^{1} \mathrm{H}-{ }^{15} \mathrm{~N}$ heteronuclear single quantum coherence (HSQC) nuclear magnetic resonance (NMR) spectroscopy at the amino acid residue level. As presented in Fig. 1d and 1e, upon treatment of APP-C31 with a solution of uniformly ${ }^{15} \mathrm{~N}$-labeled $A \beta_{40}$, we detected notable chemical shift perturbations (CSPs) of the amino acid residues Arg5, Glu11, Gln15, Leu17, Phe20, and Ala21 in A $\beta$. This observation indicates that APP-C31 could interact with the $N$-terminal region and the self-recognition site of $A \beta$ (i.e., Leu17 to Ala21; Fig. 1a). Given that the self-recognition site of $A \beta$ is a central hydrophobic region responsible for the oligomerization and fibrilization ${ }^{3,4}$, APP-C31 may alter the conformation and aggregation propensity of $A \beta$ (vide infra). Together, the abovementioned studies by MS, ITC, and 2D NMR verify that APP-C31 can interact with the $N$ terminal and self-recognition regions of $A \beta$ in a relatively weak binding manner. 
APP-C31-A $\beta$ binding modes. To obtain atomistic insight into the binding of APP-C31 to A $\beta_{40}$, a series of molecular dynamics (MD) simulations was carried out ${ }^{19-27}$. In these computer simulations, $A \beta_{40}$ (PDB 2LFM ${ }^{28}$; Fig. 2a) obtained by solution NMR was used as the starting conformation of monomeric A $\beta$. Unfortunately, the exact structure of APP-C31 is not known; thus, the X-ray crystal structure of $\mathrm{APP}_{666-693}$ excised from the intracellular domain of APP complexed with Fe65 protein (PDB 3DXC 29; Fig. 2a) was selected to provide the starting guess structure of APP-C31. Faithfully, modelling slow processes like the folding and association of peptides taking place in minutes to hours time-scale with MD simulations is challenging. One solution to accelerating the simulation and obtaining meaningful data within a tractable computing time is to first conduct metadynamics MD simulations that allow for a more rapid and efficient sampling of the unique configurational space to identify the most relevant adduct structures. We sampled dimeric configurations with the gross metadynamics simulation time being $8.4 \mu \mathrm{s}$. These simulations facilitate the conformational sampling along the center-of-mass (COM) coordinate between the pair of proteins, and provide the Gibbs free energy profile along the reaction coordinate ${ }^{19}$. The Gibbs free energy profile of the $A P P_{666-693}-\mathrm{A} \beta_{40}$ adduct suggests that the association is fully reversible. As shown in Supplementary Fig. 1, we found an ensemble of hetero-dimer conformers at the COM distance of $13 \AA$.

To verify and rank the relative stabilities of the dimeric structures, additional $500 \mathrm{~ns}$ of unbiased MD simulations without the metadynamics acceleration were performed, where the initial structures were taken from the metadynamics MD simulations. The adduct structures from the MD simulations were evaluated based on two criteria: (i) the monomers of $A \beta_{40}$ and APP666693 maintain contacts throughout the course of unbiased MD simulations (Supplementary Fig. 2); (ii) the six amino acid residues displaying the pronounced CSPs are at the dimeric interface (Supplementary Fig. 3). As illustrated in Fig. 2b, we identified two classes of stable APP ${ }_{666-693-}$ $A \beta_{40}$ dimeric adduct structures that are most consistent with our experimental results described in Fig. 1b-e. In Model I and II, the dimeric interfaces were formed by favorable intermolecular contacts and hydrogen bonding. The amino acid residues in the $\mathrm{N}$-terminal region and the self-

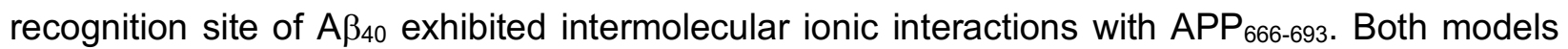
presented a salt bridge between $\operatorname{Arg} 5$ of $A \beta_{40}$ and Glu683 of APP $666-693$. In Model I, another salt

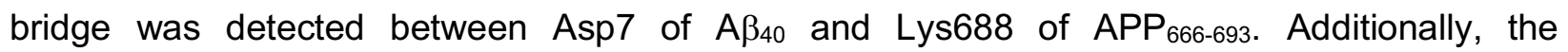
intermolecular hydrophobic contacts between the aliphatic side chain of Val18 in $A \beta_{40}$ and the aromatic rings of Tyr682, Phe689, and Phe690 in APP $666-693$ were revealed in both models. Moreover, multiple hydrogen bonds were observed in the APP $666-693-A \beta_{40}$ dimeric interfaces. The 

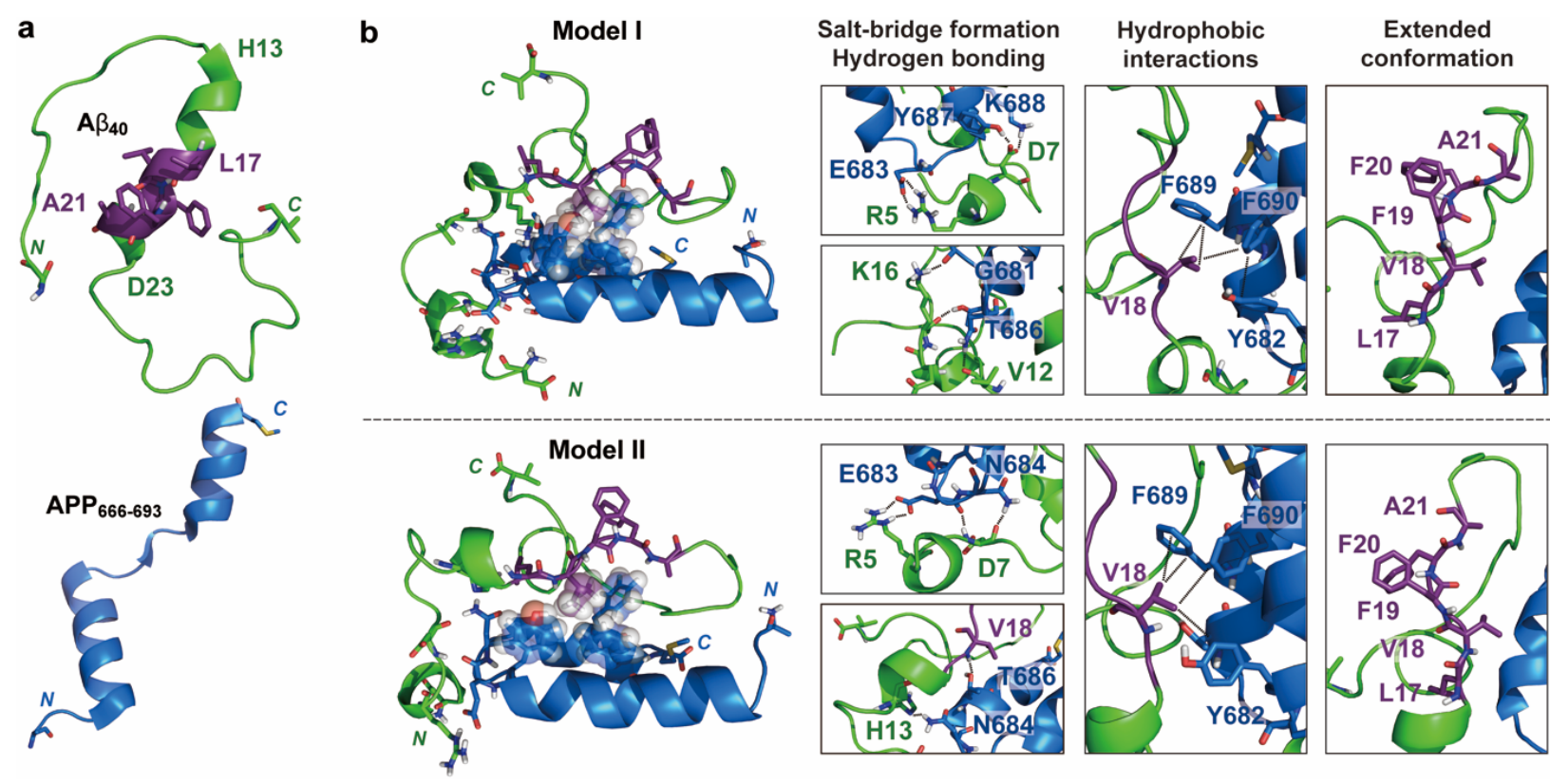

Fig. 2 | Interactions between APP-C31 and $A \beta_{40}$ visualized by metadynamics MD simulations. a, Conformations of $A \beta_{40}\left(P D B 2 L F M^{28}\right)$ and $A P P_{666-693}\left(P D B ~ 3 D X C^{29}\right)$ as a part of APP-C31 (APP $665-695)$ used for metadynamics MD simulations. The self-recognition site of $A \beta$ is highlighted in purple. b, Representative models (I and II) of the APP $666-693-A \beta_{40}$ interfaces from the trajectories of MD simulations. Possible hydrogen bonds within $3.0 \AA$ and hydrophobic interactions observed within $4.0 \AA$ are indicated with dashed black lines. The amino acid residues involved in hydrophobic interactions are presented in the space-filling representation.

Asp7 residue of $A \beta_{40}$ constructed hydrogen bonds with Tyr687 and Asn684 of APP $666-693$ in Model I and II, respectively. Furthermore, the backbone carbonyl group of Val12 and the imidazole nitrogen atom of His13 in $A \beta_{40}$, as shown in Model I and II, respectively, produced the backboneside chain and side chain-side chain hydrogen bonds with Asn684 of APP666-693, respectively. Hydrogen bonding between the backbone carbonyl and hydroxyl groups of Gly681 and Thr686 in $\mathrm{APP}_{666-693}$, respectively, and Lys16 that is adjacent to the self-recognition site of $A \beta_{40}$ was also monitored in Model I. As indicated in Model II, Thr686 of APP $666-693$ additionally formed hydrogen bonding with the backbone amide moiety of Val18 in $A \beta_{40}$.

Interestingly, our MD simulations indicated a conformational change in $A \beta$ upon binding to APP-C31. As displayed in Fig. $2 b$, the secondary structure of $A \beta_{40}$ spanning from His 13 to Asp23 became disordered, which is distinct from its monomeric form exhibiting an $\alpha$-helical structure in 
the same region (Fig. 2a). In particular, the self-recognition site of $A \beta_{40}$ highlighted in purple adopted an extended conformation. The Ramachandran plots for the amino acid residues in the self-recognition site (Leu17 to Ala21) presented their dihedral angles mostly in the region of a $\beta$ sheet and an extended helix ${ }^{30}$, as summarized in Supplementary Fig. 4. This observation suggests that the conformation of $A \beta_{40}$ can be easily converted to a $\beta$-strand in the presence of APP-C31. Although structural changes are expected during protein association, the extent of change we observed is notable and offers additional explanations for the dominance of the entropy term in the binding free energy. The $\alpha$-helical form of $A \beta_{40}$ is the most stable form allowing for favorable interactions with the surrounding water molecules. As the peptide undergoes a transition to the extended form and is incorporated into the heterodimer with APP-C31, water molecules from the $\alpha$-helix are liberated ${ }^{31}$. Furthermore, the transition to the extended motif increases the intrastrand conformational entropy that will help to compensate for the translational entropy penalty that must be paid during the hetero-dimer formation. Ultimately, in addition to intermolecular ionic and hydrophobic interactions and hydrogen bonds, such structural alteration in $A \beta$ can modify its oligomerization and fibrillization, as the self-recognition site is critically involved in peptide aggregation ${ }^{3,4}$. Overall, the results and observations by MD simulations support that APP-C31 can directly interact with the $N$-terminal region and the self-recognition site of $A \beta$ and induce its conformational transition.

Effect of APP-C31 on A $\beta$ aggregation. To assess whether APP-C31 can influence the aggregation of $A \beta$, the samples prepared with the two peptides, as described in Fig. $3 a$ and Supplementary Fig. 5a, were first analyzed by the thioflavin-T (ThT) assay that quantifies the degree of $\beta$-sheet formation ${ }^{3,32}$. We tested the two major isoforms of $A \beta, A \beta_{40}$ and $A \beta_{42}{ }^{3,4}$. As summarized in Fig. 3b, $\beta$-sheet-rich species were generated in the sample of $A \beta_{40}$ after a lag time for $1.7 \mathrm{~h}$ and the ThT fluorescence intensity plateaued at $6 \mathrm{~h}$. In the presence of APP-C31, the lag time of $A \beta_{40}$ was notably shorter than that of $A \beta_{40}$ only. When APP-C31 was treated with $A \beta_{40}$, the ThT fluorescence intensity increased after $1 \mathrm{~h}$ and reached a plateau at $3.5 \mathrm{~h}$. These results suggest that APP-C31 facilitates the aggregation of $A \beta_{40}$. Different from $A \beta_{40}$, the aggregation kinetics of $A \beta_{42}$ was not significantly affected by APP-C31 (Supplementary Fig. 5b). It should be noted that APP-C31 by itself did not change the ThT fluorescence even with longer incubation time; thus, it could not generate $\beta$-sheet-rich assemblies under our experimental conditions if no $A \beta$ was present. Notable aggregates of APP-C31 were not observed by transmission electron microscopy (TEM) (data not shown). Analysis of APP-C31 by circular dichroism (CD) 
a
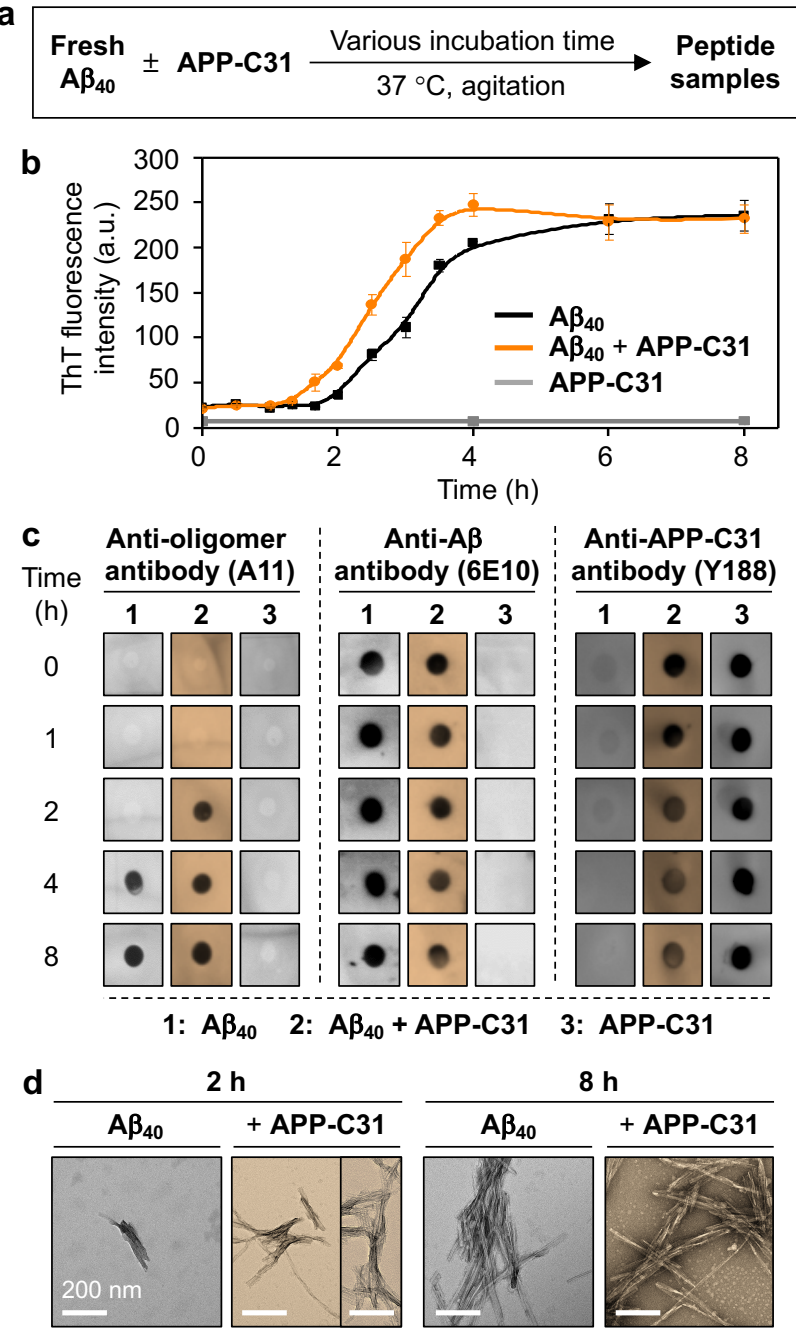

Fig. 3 | Impact of APP-C31 on $\mathbf{A} \boldsymbol{\beta}_{40}$ aggregation. a, Scheme of the aggregation experiments. b,c, Analysis of the degree on peptide aggregation upon incubation of either A $\beta_{40}$, APP-C 31 , or both by the ThT and dot blot assays, respectively. d, Morphologies of the peptide aggregates produced upon $2 \mathrm{~h}$ and $8 \mathrm{~h}$ treatment of $A \beta_{40}$ with or without APP-C31 detected by TEM. Scale bars $=200 \mathrm{~nm}$. Conditions: $\left[\mathrm{A} \beta_{40}\right]=25 \mu \mathrm{M}$ and [APP-C31] $=25 \mu \mathrm{M}$ (for ThT assay and TEM); $\left[\mathrm{A} \beta_{40}\right]=100 \mu \mathrm{M}$ and $[$ APP-C31] $=100 \mu \mathrm{M}$ (for dot blot assay); $20 \mathrm{mM} \mathrm{HEPES,} \mathrm{pH} \mathrm{7.4,} 150 \mathrm{mM}$ $\mathrm{NaCl} ; 37^{\circ} \mathrm{C}$; constant agitation.

spectroscopy further delineated that its secondary structure was not changed after $24 \mathrm{~h}$ incubation, as presented in Supplementary Fig. 6.

Next, the impact of APP-C31 on the oligomerization of A $\beta$ was probed by the dot blot assay employing three different antibodies including an anti-oligomer antibody $(\mathrm{A} 11)^{33}$, an anti-A $\beta$ 
antibody $(6 \mathrm{E} 10)^{34}$, and an anti-APP $\mathrm{C}$-terminus antibody $(\mathrm{Y} 188)^{35}$. As illustrated in Fig. 3c, the A11 signal appeared from the sample of $A \beta_{40}$ incubated with APP-C31 after $2 \mathrm{~h}$ while $A \beta_{40}$ in the absence of APP-C31 showed the A11 signal after $4 \mathrm{~h}$. These results are consistent with the accelerated oligomerization of $A \beta_{40}$ by interacting with APP-C31, as proposed above. Similar to the ThT assay, the dot blot indicated no noticeable effect of APP-C31 on the oligomerization of $A \beta_{42}$ (Supplementary Fig. 5c). Lastly, morphologies of the $A \beta$ aggregates produced upon addition of APP-C31 were visualized by TEM. Long linear $A \beta_{40}$ fibrils were detected from the sample containing $A \beta_{40}$ and APP-C31 even at the early aggregation stage, compared to short fibrils formed by $A \beta_{40}$ only, as depicted in Fig. $3 d$. The change in the morphology of $A \beta_{42}$ aggregates was also observed by treatment of APP-C31, as shown in Supplementary Fig. $5 \mathrm{~d}$, which is distinct from the results by the ThT and dot blot assays. When $A \beta_{42}$ was incubated with APP-C 31 for $2 \mathrm{~h}$ and $8 \mathrm{~h}$, long straight $A \beta_{42}$ fibrils were monitored in contrast to smaller aggregates or bundled fibrils generated by incubation of $A \beta_{42}$ only. Collectively, our aggregation studies corroborate that APP-C31 is capable of promoting the oligomerization and fibrilization of $A \beta$.

Interactions of APP-C31 with metals and metal-A $\beta$ and its impact on metal-A $\beta$ aggregation. Under normal brain conditions, metal ions are tightly regulated and play crucial roles in neurotransmission, protein folding, and enzymatic reactions ${ }^{3}$. In AD-afflicted brains, however, metal ion dyshomeostasis and highly concentrated metals trapped in senile plaques such as ca. $400 \mu \mathrm{M}$ of copper and ca. $1 \mathrm{mM}$ of zinc are found ${ }^{3,36}$. Additionally, the accumulation of $A \beta$ aggregates with metal ions is detected in intracellular systems ${ }^{37,38}$. Metal ions including $\mathrm{Cu}(\mathrm{I} / \mathrm{II})$ and $\mathrm{Zn}(\mathrm{II})$ can coordinate to $A \beta$ forming metal-bound $A \beta$ (metal-A $\beta$ ) and subsequently affect $A \beta$ aggregation pathways to different degrees depending on the type of metal ions and metal-to-A $\beta$ stoichiometry ${ }^{3,36}$. Under these notions, the interactions of APP-C31 with metal ions and metal-A $\beta$ were investigated.

Binding of APP-C31 to $\mathrm{Cu}(\mathrm{II})$ and $\mathrm{Zn}(\mathrm{II})$ was determined by ESI-MS and ITC. As presented in Supplementary Fig. 7, when APP-C31 was added with $\mathrm{Cu}(\mathrm{II}), \mathrm{ESI}-\mathrm{MS}$ studies exhibited the $\mathrm{Cu}(\mathrm{II})-\mathrm{APP}-\mathrm{C} 31$ complexation with indication of the peak corresponding to $[\mathrm{Cu}(\mathrm{II})+\mathrm{APP}-\mathrm{C} 31]^{4+}$. Zn(II)-bound APP-C31 was not observed under our experimental conditions for our MS studies. Binding events between APP-C31 and Cu(II) or $\mathrm{Zn}$ (II) were further analyzed by ITC, as shown in Supplementary Fig. 8. When $\mathrm{Cu}(\mathrm{II})$ was titrated to APP-C31, an exergonic reaction was observed $(\Delta G=-6.5( \pm 0.1) \mathrm{kcal} / \mathrm{mol} ; \Delta H=-0.5( \pm 0.1) \mathrm{kcal} / \mathrm{mol} ; T \Delta S=6.0( \pm 0.1) \mathrm{kcal} / \mathrm{mol})$ with the dissociation constant $\left(K_{d}\right)$ value of $8.7( \pm 1.5) \mu \mathrm{M}$. Similarly, binding of APP-C31 to Zn(II) was also 
exergonic $(\Delta G=-6.2( \pm 0.1) \mathrm{kcal} / \mathrm{mol} ; \Delta H=0.3( \pm 0.1) \mathrm{kcal} / \mathrm{mol} ; T \Delta S=6.5( \pm 0.1) \mathrm{kcal} / \mathrm{mol})$. The $K_{d}$ value of $\mathrm{Zn}(\mathrm{II})-$ APP-C31 was determined to be $18.0( \pm 4.6) \mu \mathrm{M}$. Curiously, the metal-binding enthalpies are essentially thermoneutral at -0.5 and $0.3 \mathrm{kcal} / \mathrm{mol}$ for $\mathrm{Cu}(\mathrm{II})$ and $\mathrm{Zn}(\mathrm{II})$, respectively. Thus, metal binding is dominated by favorable entropy components of the free energy. As explained when discussing the heterodimer formation, this finding is counter intuitive, but it is likely caused by the release of water molecules that were tightly bound to the metal ion in the first solvent shell and become free water molecules as the metal ion binds to the peptide. The signs of enthalpy of binding may imply that APP-C31 presents either different binding sites or the structural arrangements around $\mathrm{Cu}(\mathrm{II})$ and $\mathrm{Zn}(\mathrm{II})$ distinctively different ${ }^{39,40}$. Given that the $K_{d}$ values of $\mathrm{Cu}(\mathrm{II})-\mathrm{A} \beta_{40}$ and $\mathrm{Zn}(\mathrm{II})-\mathrm{A} \beta_{40}$ are $10^{-10} \mathrm{M}$ and $10^{-6} \mathrm{M}$, respectively, ${ }^{3,36}$, APP-C31 may not be able to extract the metal ion from metal-bound $A \beta$. As illustrated in Fig. 4a and Supplementary Fig. 9, the interaction of APP-C31 with $\mathrm{Cu}(\mathrm{II})$-treated $\mathrm{A} \beta$ was verified by ESI-MS. The sample containing APP-C31, $A \beta_{40}$, and $\mathrm{Cu}(\mathrm{II})$ in a molar ratio of $1: 1: 1$ presented the peaks assigned to $\left[\mathrm{Cu}(\mathrm{II})+\mathrm{A} \beta_{40}+\mathrm{APP}-\mathrm{C} 31\right]^{5+}$ and $\left[2 \mathrm{Cu}(\mathrm{II})+\mathrm{A} \beta_{40}+\mathrm{APP}-\mathrm{C} 31\right]^{5+}$. Furthermore, the peak corresponding to $\left[\mathrm{Zn}(\mathrm{II})+\mathrm{A} \beta_{40}+\mathrm{APP}-\mathrm{C} 31\right]^{5+}$ with a low intensity was monitored when APP-C31 was incubated with $\mathrm{Zn}(\mathrm{II})$-added $\mathrm{A} \beta$, as presented in Fig. 4a and Supplementary Fig. 10. Together, our binding studies confirm the direct interactions of APP-C31 with metal ions and metal-A $\beta$.

Moving forward, the effects of APP-C31 on the aggregation of metal-A $\beta$ were examined by the ThT assay, the dot blot assay, and TEM. As depicted in Fig. 4b and 4c, APP-C31 expedited the aggregation of both $\mathrm{Cu}(\mathrm{II})-\mathrm{A} \beta_{40}$ and $\mathrm{Zn}(\mathrm{II})-\mathrm{A} \beta_{40}$ to different extents. $A \beta_{40}$ treated with $\mathrm{Cu}(\mathrm{II})$ and APP-C31 rapidly aggregated displaying a lag phase of approximately $4 \mathrm{~h}$ and produced more ThT-reactive $\beta$-sheet-rich aggregates, relative to $\mathrm{Cu}(\mathrm{II})-\mathrm{A} \beta_{40}$ only. The oligomerization of $\mathrm{Cu}(\mathrm{II})-$ A $\beta_{40}$ was also promoted by APP-C31, as analyzed by the dot blot assay (Supplementary Fig. 11). In the case of $\mathrm{Zn}(\mathrm{II})$-treated $\mathrm{A} \beta_{40}$, incubation with APP-C31 led to the facilitated aggregation kinetics with the saturated ThT fluorescence at $8 \mathrm{~h}$ and the reduction of forming ThT-reactive $\beta$ sheet-rich $A \beta_{40}$ aggregates by ca. 25\%. It should be noted that APP-C31 with $\mathrm{Cu}(\mathrm{II})$ and $\mathrm{Zn}(\mathrm{II})$ in the absence of $A \beta_{40}$ did not change the ThT fluorescence, suggesting no conformational transition to a $\beta$-sheet-rich form under our experimental conditions.

As illustrated in Fig. 4d, when $\mathrm{Cu}(\mathrm{II})$-added $\mathrm{A} \beta_{40}$ was incubated with APP-C31 for $8 \mathrm{~h}, 24 \mathrm{~h}$, and $72 \mathrm{~h}$, shorter and thicker fibrils were detected by TEM, different from fibrils produced from APP-C31-untreated $\mathrm{Cu}(\mathrm{II})-\mathrm{A} \beta_{40}$. Additionally, short fibrils over amorphous aggregates were present from the sample of $\mathrm{Zn}(\mathrm{II})-\mathrm{A} \beta_{40}$ treated with APP-C31 for $8 \mathrm{~h}$ and $24 \mathrm{~h}$. After longer incubation (i.e., $72 \mathrm{~h}$ ), no significant morphological difference between the samples of $\mathrm{Zn}(\mathrm{II})$ - 


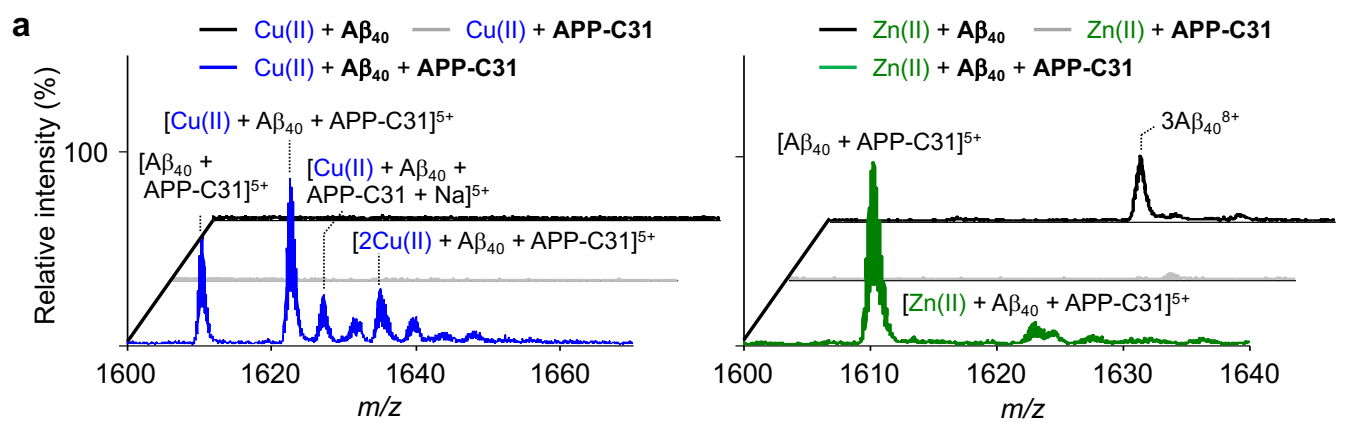

b
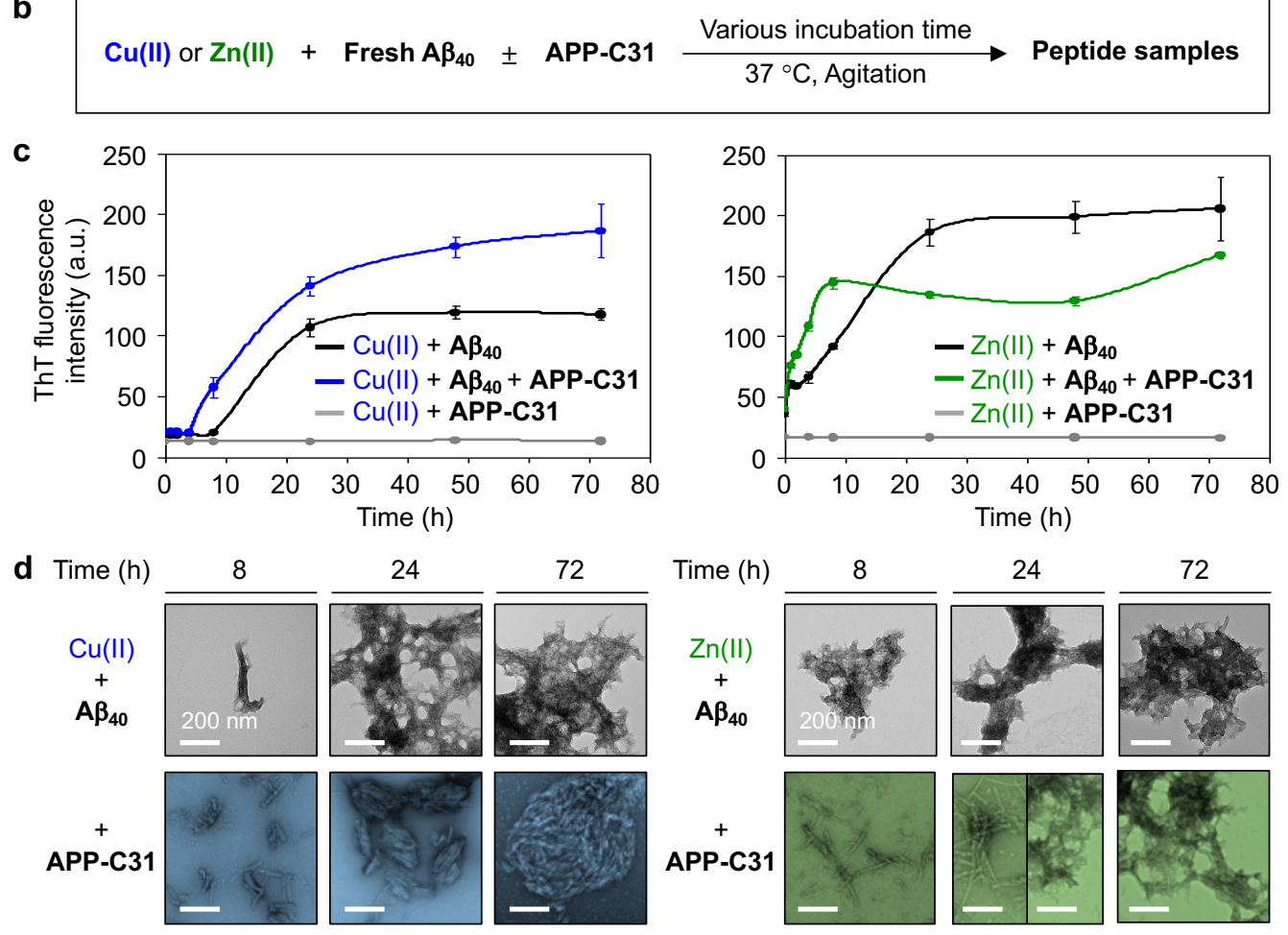

Fig. 4 | Interactions of APP-C31 with metal-treated A $\beta$ and its influence on metal-induced $\mathbf{A} \boldsymbol{\beta}$ aggregation. a, ESI-MS spectra of $\mathrm{Cu}(\mathrm{II})$ - or $\mathrm{Zn}(\mathrm{II})$-added $\mathrm{A} \beta_{40}$ with and without APP-C31 and $\mathrm{Cu}(\mathrm{II})$ - or $\mathrm{Zn}(\mathrm{II})$-treated APP-C31. The full MS spectra are depicted in Supplementary Fig. 9 and 10. Conditions: $\left[\right.$ APP-C31] $=100 \mu \mathrm{M} ;\left[\mathrm{A} \beta_{40}\right]=100 \mu \mathrm{M} ;\left[\mathrm{CuCl}_{2}\right.$ or $\left.\mathrm{ZnCl}_{2}\right]=100 \mu \mathrm{M} ; 20 \mathrm{mM}$ ammonium acetate, $\mathrm{pH} 7.3 ; 37^{\circ} \mathrm{C} ; 2 \mathrm{~h}$ incubation; no agitation; 10 -fold diluted samples were injected to the mass spectrometer. $\mathbf{b}$, Scheme of the aggregation experiments. $\mathbf{c}$, Analysis of the degree on peptide aggregation upon incubation of either metal-added $A \beta_{40}$, metal-treated APP. C31, or both by the ThT assay. d, Morphologies of the peptide aggregates generated by 8 h, 24 $h$, and $72 \mathrm{~h}$ incubation of metal-treated $A \beta_{40}$ with and without APP-C31 monitored by TEM. Scale bars $=200 \mathrm{~nm}$. Conditions for the ThT assay and TEM: $\left[\right.$ APP-C31] $=25 \mu \mathrm{M} ;\left[\mathrm{A} \beta_{40}\right]=25 \mu \mathrm{M}$; $\left[\mathrm{CuCl}_{2}\right.$ or $\left.\mathrm{ZnCl}_{2}\right]=25 \mu \mathrm{M} ; 20 \mathrm{mM} \mathrm{HEPES}, \mathrm{pH} 7.4,150 \mathrm{mM} \mathrm{NaCl} ; 37^{\circ} \mathrm{C}$; constant agitation. 
added $A \beta_{40}$ with and without APP-C31 was monitored. Similar to metal-free $A \beta_{42}$, the aggregation of metal-A $\beta_{42}$ was much less modified by APP-C31. As depicted in Supplementary Fig. 12 and 13, APP-C31 did not alter the aggregation kinetics of metal-added A $\beta_{42}$. The amount of ThTreactive $\beta$-sheet-rich aggregates produced by interacting $\mathrm{Zn}(\mathrm{II})-\mathrm{A} \beta_{42}$ with APP-C31 was lowered by approximately $35 \%$, compared to that from $\mathrm{Zn}(\mathrm{II})-\mathrm{A} \beta_{42}$ only, but morphologies of the resultant $A \beta_{42}$ aggregates from both samples were similar. Overall, our investigations confirm that APPC31 accelerates the aggregation of metal-A $\beta_{40}$.

Cytotoxicity of A $\beta$ associated with APP-C31. We performed microinjection experiments in living cells to identify the impact of APP-C31 towards the toxicity triggered by intracellular A $\beta$. As described in Fig. 5a, A $\beta_{40}$ with or without APP-C31 in the absence and presence of metal ions was introduced inside the cells with Texas Red-labeled dextran that is an indicator for the cells injected with the samples ${ }^{41}$. After $24 \mathrm{~h}$ incubation, cell viability was determined by counting the Texas Red-positive cells following previously reported methods ${ }^{42}$. The cells injected with either APP-C31 or A $\beta_{40}$ under our experimental conditions exhibited ca. $95 \%$ of cell survival, as presented in Fig. 5b. When both APP-C31 and A $\beta_{40}$ were administered inside the cells, cell death was enhanced by ca. $40 \%$. In the case of $\mathrm{Cu}(\mathrm{II})$ - and $\mathrm{Zn}(\mathrm{II})$-added $\mathrm{A} \beta_{40}$, the viability was approximately $80 \%$ and $90 \%$, respectively. Upon addition of metal-treated A $\beta_{40}$ with APP-C31 inside the cells, cell survival was further decreased by ca. $10 \%$. Thus, our microinjection studies demonstrate that APP-C31 aggravates the cytotoxicity of intracellular A $\beta$ with and without metal ions to different degrees.

To further identify whether the cell death induced by treating both APP-C31 and A $\beta$ is associated with apoptosis that is a type of programmed cell death ${ }^{43}$, live-cell imaging experiments using annexin $\mathrm{V}$ staining were carried out. Annexin $\mathrm{V}$ conjugated with Alexa Fluor 488 can stain externalized phosphatidylserine in apoptotic cells, thereby emitting green fluorescence ${ }^{43}$. The overlap between green and red fluorescence from annexin $\mathrm{V}$ and Texas Red-labeled dextran, respectively, indicates the cells that are injected with the samples and undergo apoptosis. The degree of the colocalization between green and red fluorescence was analyzed by the Pearson's coefficient $(r)$, a type of the correlation coefficient that represents the strength of the association between the two variables ${ }^{44}$. When APP-C31 or A $\beta_{40}$ was added inside the cells followed by $24 \mathrm{~h}$ incubation, the cells did not show significant green fluorescence of annexin V, as displayed in Fig. $5 \mathrm{c}$. The $r$ value was approximately 0.2 , indicative of the poor association between apoptosis and the internalization of APP-C31 or A $\beta_{40}$ under our experimental conditions. Notably, the injection 

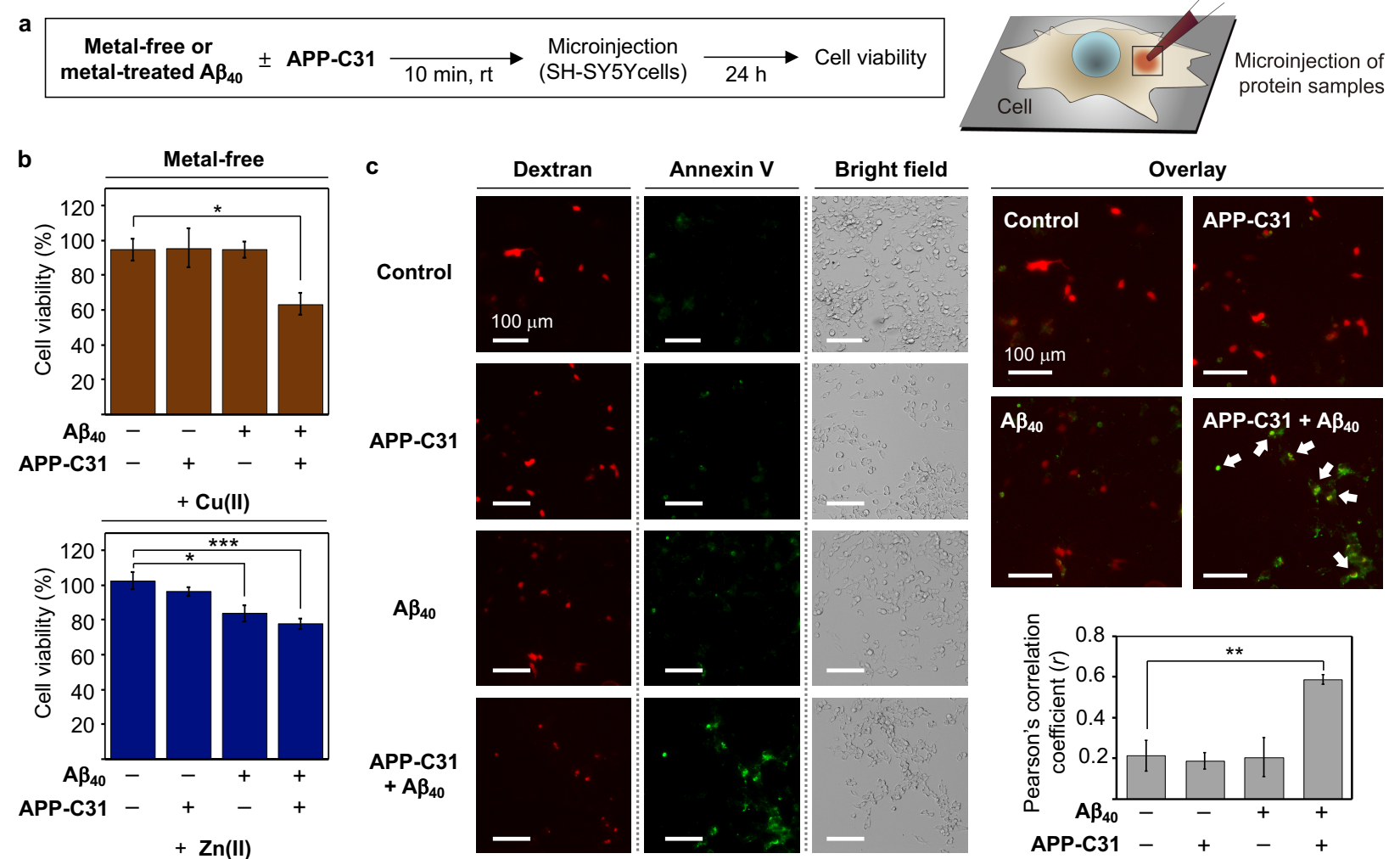

Annexin V
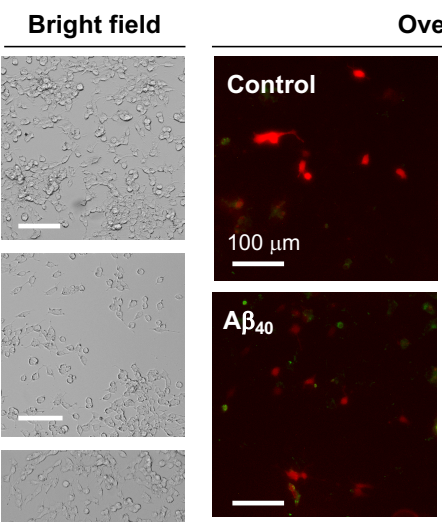

Overlay
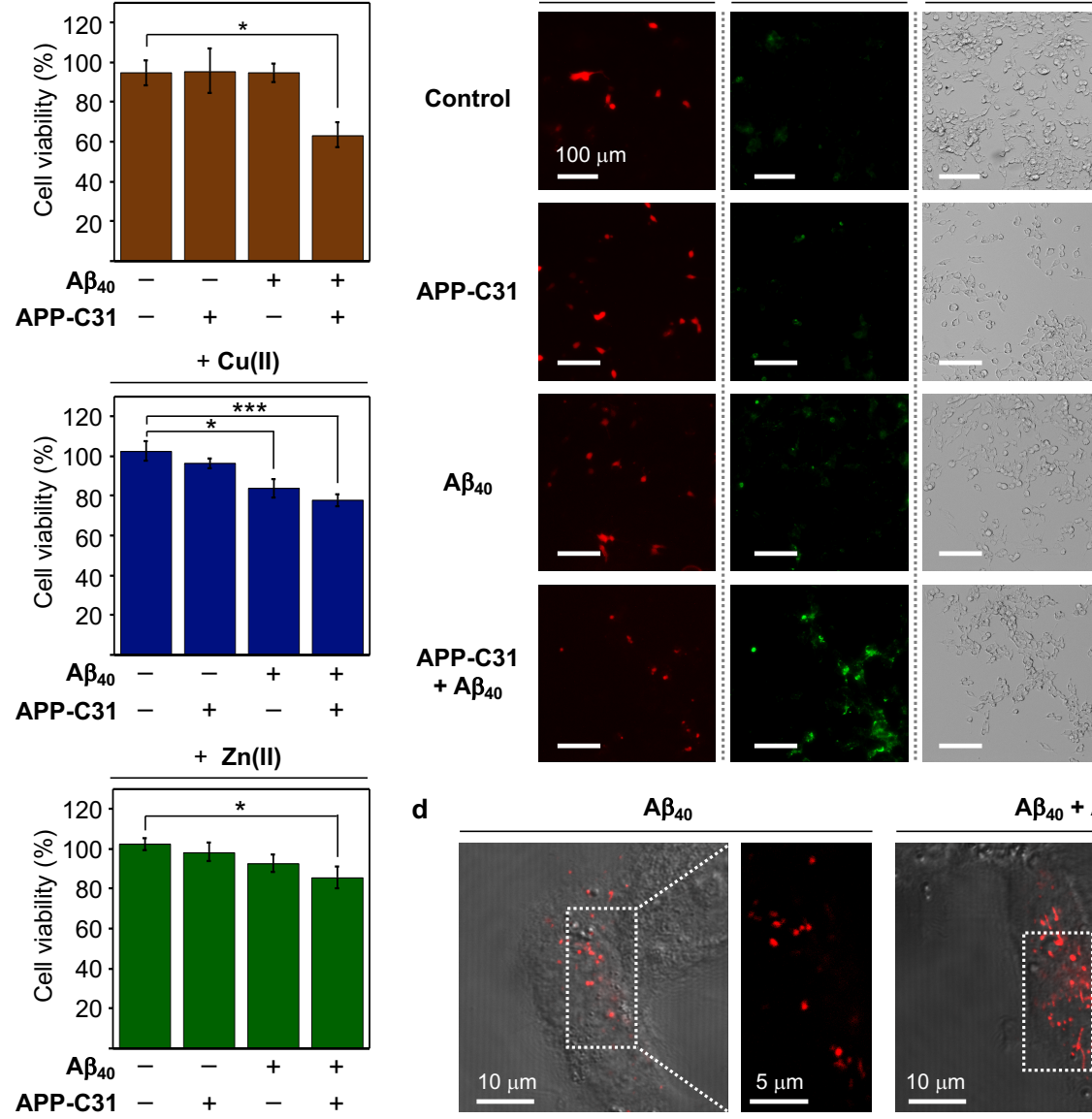

d
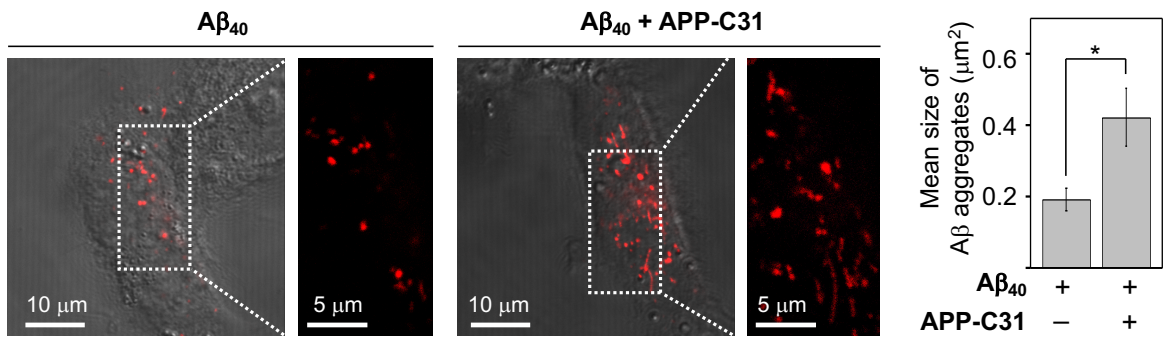

e
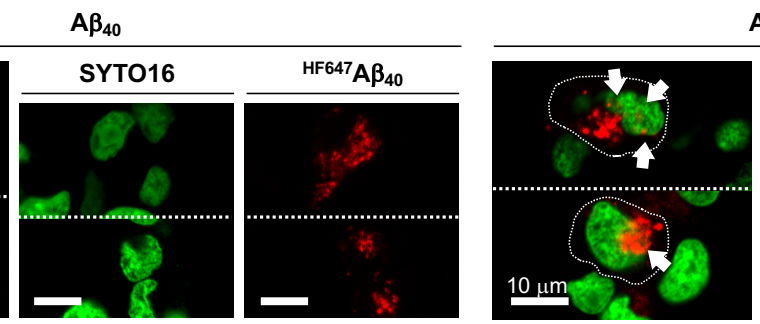

$A \beta_{40}+A P P-C 31$
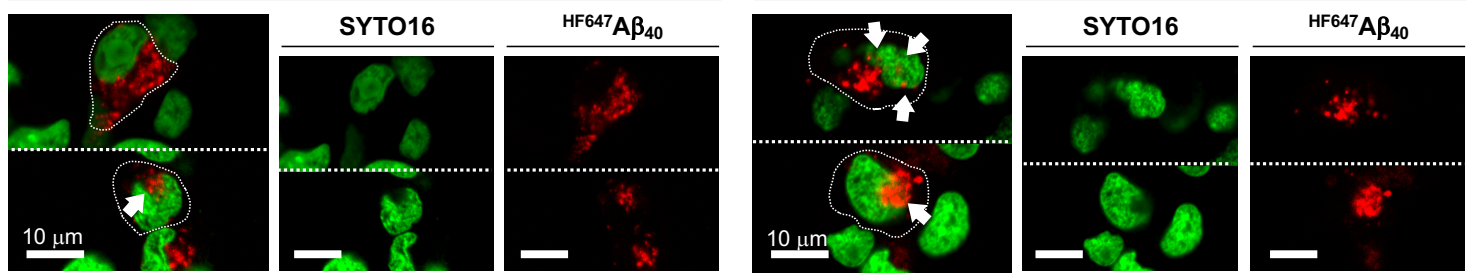

Fig. 5 | Influence of APP-C31 on the toxicity and aggregation of intracellular A $\beta$. a, Scheme of the microinjection experiments. $\mathbf{b}$, Cell viability of SH-SY5Y cells microinjected with either APPC31, $A \beta_{40}$, or both in the absence and presence of metal ions. Measurements of cell survival were described in detail in the experimental section. Conditions: $\left[\mathrm{A} \beta_{40}\right]=10 \mu \mathrm{M}$; $[$ APP-C31] $=10 \mu \mathrm{M}$; $\left[\mathrm{CuCl}_{2}\right.$ or $\left.\mathrm{ZnCl}_{2}\right]=10 \mu \mathrm{M}$; [Texas Red-labeled dextran] $=0.4 \mathrm{mg} / \mathrm{mL} ; 24 \mathrm{~h}$ incubation. All values denote mean \pm s.e.m. ${ }^{*} P<0.05 ;{ }^{* *} P<0.001 ; \mathrm{n}=3-5$; Student's $t$-test. c, Apoptosis monitored using Alexa Fluor 488-tagged annexin V. Pearson's correlation coefficients were calculated to 
present the colocalization of the fluorophore-tagged dextran and Annexin $\mathrm{V}$ (mean \pm s.e.m, ${ }^{* *} P<$ $0.01 ; n=5$; Student's $t$-test). White arrows indicate apoptotic cells microinjected with peptide samples. Conditions: $\left[\mathrm{A} \beta_{40}\right]=10 \mu \mathrm{M}$; $[$ APP-C31 $]=10 \mu \mathrm{M}$; $[$ Texas Red-labeled dextran $]=0.4$ $\mathrm{mg} / \mathrm{mL} ; 24 \mathrm{~h}$ incubation. Scale bars $=100 \mu \mathrm{m}$. d, Mean size of intracellular $A \beta_{40}$ aggregates in the absence and presence of APP-C31 observed in the airyscan confocal images. Aggregates (red) with dimensions exceeding the resolution limit were analyzed. Conditions: $\left[{ }^{\mathrm{HF} 647} \mathrm{~A} \beta_{40}\right]=10$ $\mu \mathrm{M}$; [APP-C31] = $10 \mu \mathrm{M} ; 24 \mathrm{~h}$ incubation. Scale bars $=5$ and $10 \mu \mathrm{m}$. Data are represented as mean \pm s.e.m. $n=52$ for the group of ${ }^{\mathrm{HF} 647} A \beta_{40} ; n=63$ for the group of ${ }^{\mathrm{HF} 647} \mathrm{~A} \beta_{40}$ with APP-C31; ${ }^{*} P<0.05$; Student's $t$-test. The size distributions of $A \beta_{40}$ aggregates in both groups were summarized in Supplementary Fig. 14. e, Intranuclear transmission of $A \beta_{40}$ aggregates (red) with and without APP-C31. Nuclei were stained with SYTO16 (green). Conditions: $\left[{ }^{\mathrm{HF} 647} \mathrm{~A} \beta_{40}\right]=10 \mu \mathrm{M}$; $[$ APP-C31] $=10 \mu \mathrm{M} ;[$ SYTO16] $=2.5 \mu \mathrm{M} ; 24 \mathrm{~h}$ incubation. Scale bars $=10 \mu \mathrm{m}$.

of both APP-C31 and $A \beta_{40}$ into the cells resulted in the intense green fluorescence of annexin $V$ with the $r$ value of ca. 0.64 . Clearly, these results illuminate that the intracellular presence of the two peptides can cause apoptosis.

Given that intracellular $A \beta$ species can induce apoptosis via damaging organelles and membranes ${ }^{2,4,43}$, we examined the influence of APP-C31 on accumulating A $\beta$ aggregates at the intracellular level employing a fluorophore-labeled $A \beta_{40}$ and high-resolution confocal microscopy. The size of individual $A \beta_{40}$ aggregates was determined by counting the pixels of the fluorescent area based on previously reported procedures ${ }^{45,46}$. The HiLyte Fluor 647-conjugated $A \beta_{40}$ $\left({ }^{\mathrm{HF} 647} \mathrm{~A} \beta_{40}\right)$ with and without APP-C31 was injected into the cytoplasm of the cells. After $24 \mathrm{~h}$ incubation, ${ }^{H F 647} A \beta_{40}$ in the absence of APP-C31 exhibited a cluster of spherical aggregates with an average size of ca. $0.19 \mu \mathrm{m}^{2}$, as illustrated in Fig. 5d and Supplementary Fig. 14. When ${ }^{H F 647} A \beta_{40}$ with APP-C31 was introduced inside the cells, we identified enlarged $A \beta_{40}$ aggregates with a cluster size of ca. $0.42 \mu \mathrm{m}^{2}$. The intracellular distribution of ${ }^{\mathrm{HF} 647} \mathrm{~A} \beta_{40}$ aggregates was further monitored in the cells stained with the fluorescent SYTO16 dye that can visualize nuclei by binding to nucleic acids ${ }^{47}$, as depicted in Fig. 5 e. A $\beta_{40}$ aggregates without APP-C31 were mostly located in the cytoplasm and a few clusters of them were internalized at the nucleus, as highlighted with white arrows shown in Fig. 5e. When ${ }^{\mathrm{HF} 647} \mathrm{~A} \beta_{40}$ was injected with APP-C31 into the cells, we observed intranuclear $A \beta_{40}$ aggregates. Furthermore, the bulky $A \beta_{40}$ aggregates were invaded 
into the nucleus. Therefore, our findings support that APP-C31 can promote the deposition of A $\beta$ aggregates at the nuclear and perinuclear regions and, consequently, damage the nucleus leading to apoptosis.

Moreover, the effect of $A \beta$ species treated with APP-C31 towards human neuronal growth was investigated with human neurons that are differentiated from $\mathrm{H} 9$ human embryonic stem cells. $A \beta_{40}$ was introduced with and without APP-C31 into the media of human neurons. After $24 \mathrm{~h}$ and $72 \mathrm{~h}$ incubation, the length of neurites was measured to monitor the neuronal growth, as shown in Fig. 6a. Neurons incubated with $A \beta$ in the absence and presence of APP-C31 for 24 h exhibited slightly shortened neurites by ca. $10 \%$, compared to those of vehicle-added neurons. Upon treating neurons with $A \beta_{40}$ only for $72 \mathrm{~h}$, as indicated in Fig. $6 \mathrm{~b}$ and $6 \mathrm{c}$, the length of neurites was reduced by ca. 35\%. More notably, administration of both APP-C31 and A $\beta$ to neurons led to an approximately $70 \%$ decrease in the length of neurites exhibiting the fragmentation of neurites. These observations suggest that $A \beta$-induced degeneration of neurites can be intensified by APPC31. Taken together, our studies employing cells and neurons manifest that APP-C31 can detrimentally impact the toxicity of $A \beta$.
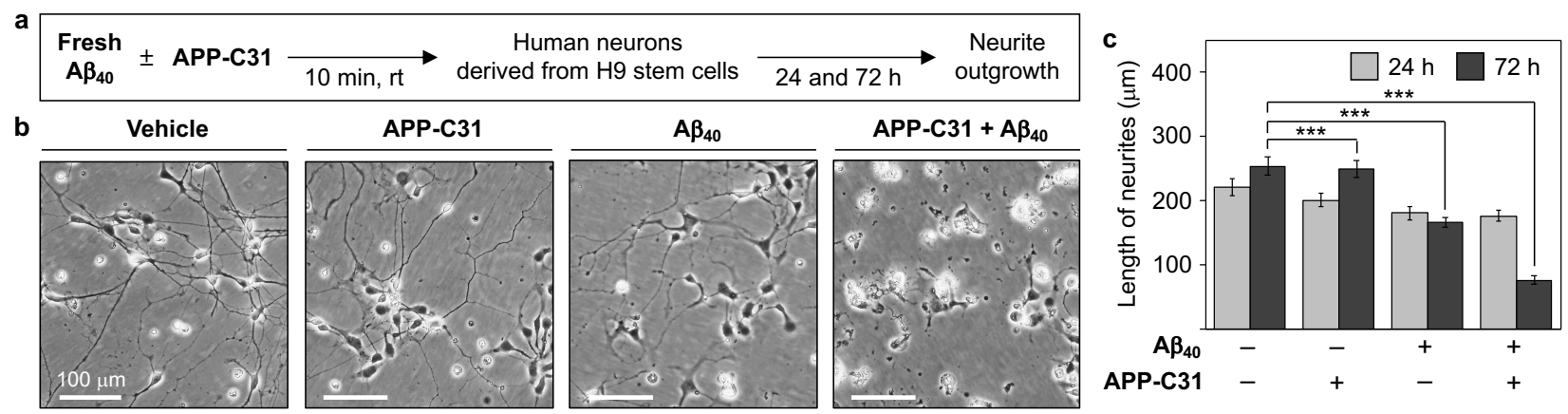

Fig. 6 | Impact of APP-C31 on the neurodegeneration induced by A $\beta$. a, Scheme of the experiments. b, Representative images of neurons after $72 \mathrm{~h}$ incubation with either APP-C31, $A \beta_{40}$, or both. $\mathbf{c}$, Average length of neurites quantified by NeuronJ in Fiji software. At least 25 neurons were analyzed per each condition. Conditions: $\left[\mathrm{A} \beta_{40}\right]=20 \mu \mathrm{M}$; $[$ APP-C31] $=20 \mu \mathrm{M}$; incubation for 24 and $72 \mathrm{~h}$. Scale bars $=100 \mu \mathrm{m}$. Data are represented as mean \pm s.e.m. ${ }^{* *} P<$ 0.001 ; Student's $t$-test.

\section{Discussion}

APP-C31 is a peptide composed of 31 amino acid residues that is generated by cleaving the 
intracellular $C$-terminal region of APP by caspases ${ }^{1}$. This peptide has been suggested to be a toxic APP fragment, along with $A \beta$, that could cause synaptic damage and neurodegeneration ${ }^{1,7,9,10}$. An inter-relationship among the activation of caspases, the intracellular $C$-terminal cleavage of APP, and $A \beta$-induced toxicity towards amyloid pathology has been recently proposed ${ }^{11}$. But to date, it was not known that APP-C31 can directly interact with A $\beta$ and alter the folding behavior that ultimately leads to the $A \beta$-related toxicity. To the best of our knowledge, this work is the first report to illuminate the effects of APP-C31 on the aggregation and toxicity of $A \beta$ through their direct contacts at both the intracellular and extracellular levels. In addition, such influence can be varied in the presence of metal ions such as $\mathrm{Cu}$ (II) and $\mathrm{Zn}$ (II) that bind to $A \beta$ species in the $A D$-affiliated brain.

The interaction between APP-C31 and $A \beta_{40}$ is relatively weak exhibiting a micromolar binding affinity that is still in the range of triggering conformational variations in intrinsically disordered proteins ${ }^{17}$. Through the contacts onto the $N$-terminal region and the self-recognition site of $A \beta_{40}$, APP-C31 forms a hetero-dimer with $A \beta$. Our computer simulations suggest that upon complexation with APP-C31, $A \beta_{40}$ unfolds the $\alpha$-helical segment at the self-recognition site that is critical for the aggregation of $A \beta^{3,4}$. This structural rearrangement facilitates the $\beta$-sheet formation. The interactions between the two peptides change the aggregation of $A \beta_{40}$ and promote the generation of elongated amyloid fibrils. In the case of $A \beta_{42}$, the aggregation is much less affected by APP-C31, which may be due to the fast kinetics and polymorphism of $A \beta_{42}$ fibrillization leading to fewer contacts between APP-C31 and $A \beta_{42}{ }^{4,48}$. APP-C31 can interact with $\mathrm{Cu}(\mathrm{II})-\mathrm{A} \beta_{40}$ and $\mathrm{Zn}(\mathrm{II})-\mathrm{A} \beta_{40}$ and accelerate their aggregation, similar to metal-free $A \beta_{40}$. In living cells, larger $A \beta_{40}$ aggregates are intracellularly produced in the presence of APP-C31. APP-C31 can noticeably induce the perinuclear and intranuclear deposition of $A \beta_{40}$ aggregates. APP-C31 may assist in translocating $A \beta$ into the perinuclear region or nuclei because the $C$-terminal fragments of APP are reported to transfer into nuclei after being complexed with other proteins ${ }^{49,50}$. This is further supported by the recent findings that perinuclear $A \beta$ aggregates are colocalized with the $C$ terminal region of $A P P^{14,15}$. Moreover, $A \beta_{40}$ incubated with APP-C31 significantly suppresses the outgrowth of neurites in human neurons. Clearly, APP-C31 can exacerbate the toxicity mediated by $A \beta$. Our combined experimental and theoretical studies demonstrate that direct interactions of APP-C31 with metal-free $A \beta$ and metal-A $\beta$ transform their aggregation and toxicity profiles under intracellular and extracellular environments.

\section{Methods}


Materials and methods. All reagents were purchased from commercial suppliers and used as received unless otherwise stated. APP-C31 (AAVTPEERHLSKMQQNGYENPTYKFFEQMQN) was purchased from AnaSpec (Fremont, CA, USA). A $\beta_{40}$ (DAEFRHDSGYEVHHQKLVFFAEDVGSNKGAIIGLMVGGVV) and $A \beta_{42}$ (DAEFRHDSGYEVHHQKLVFFAEDVGSNKGAllGLMVGGVVIA) were obtained from Peptide Institute, Inc. (Osaka, Japan). ${ }^{H F 647} A \beta_{40}$ was purchased from AnaSpec. Double-distilled water $\left(\mathrm{ddH}_{2} \mathrm{O}\right)$ used for all experiments was obtained from a Milli-Q Direct 16 system (Merck KGaA, Darmstadt, Germany). Trace metal contamination was removed from the solutions used for $A \beta$ experiments by treating Chelex (Sigma-Aldrich, St. Louis, MO, USA) overnight. The concentrations of peptides were determined by an Agilent 8453 UV-visible spectrophotometer (Agilent, Santa Clara, CA, USA). Experiments by ESI-MS were performed by an Agilent 6530 Accurate Mass Quadrupole Time-of-Flight (Q-TOF) mass spectrometer with an ESI source (Agilent). NMR spectroscopy was conducted by an AVANCE II900 spectrometer (Bruker BioSpin, Rheinstetten, Germany) equipped with a cryogenic probe. ITC was performed by a VP-ITC instrument equipped with a motor driven syringe (Malvern Panalytical, Malvern, UK). The secondary structure of APP-C31 was analyzed by a JASCO-815 150-L CD spectropolarimeter [KAIST Analysis Center for Research Advancement (KARA), Daejeon, Republic of Korea]. The membranes obtained by the dot blot assay were visualized on a ChemiDoc MP Imaging System (Bio-Rad, Hercules, CA, USA). Morphological changes of peptide aggregates were monitored by a Tecnai F20 transmission electron microscope (KARA, Daejeon, Republic of Korea). A SpectraMax M5 microplate reader (Molecular Devices, Sunnyvale, CA, USA) was employed to measure fluorescence values for the ThT fluorescence assay. Live-cell microinjection experiments were carried out by the combined system composed of a micromanipulator (InjectMan 4, Eppendorf, Hamburg, Germany) and a microinjector (Femtojet 4i, Eppendorf, Hamburg, Germany). Fluorescence analysis of living cells was conducted by an EVOS FL fluorescence microscope (Advanced Microscopy Group, Bothell, WA, USA). Confocal microscopic images were taken by Zeiss LSM 880 (KARA, Daejeon, Republic of Korea).

Preparation of APP-C31 and A 3 . APP-C31 and $A \beta$ were dissolved in $\mathrm{dd}_{2} \mathrm{O}$ and ammonium hydroxide $\left(\mathrm{NH}_{4} \mathrm{OH} ; 1 \% \mathrm{w} / \mathrm{w}\right.$, aq), respectively. After lyophilizing the resulting solutions, the peptides were stored at $-80^{\circ} \mathrm{C}$. A stock solution of $A \beta$ was prepared by dissolving the lyophilized peptide with $\mathrm{NH}_{4} \mathrm{OH}(1 \%$ w/w, aq; $10 \mu \mathrm{L})$ and diluting with $\mathrm{dd}_{2} \mathrm{O}$, as previously reported ${ }^{32,34}$. A stock solution of APP-C31 was prepared by dissolving the lyophilized peptide in $\mathrm{ddH}_{2} \mathrm{O}$. The concentration of $A \beta_{40}$ or $A \beta_{42}$ was determined by measuring the absorbance of the solution at 280 
$\mathrm{nm}\left(\varepsilon_{280}=1,450 \mathrm{M}^{-1} \mathrm{~cm}^{-1} \text { and } 1,490 \mathrm{M}^{-1} \mathrm{~cm}^{-1} \text {, respectively }\right)^{32,34}$. The concentration of APP-C31 was determined based on the extinction coefficient $\left(\varepsilon_{280}=2,980 \mathrm{M}^{-1} \mathrm{~cm}^{-1}\right)$ obtained from the ExPASy ProtParam online tool.

ESI-MS. APP-C31 $(100 \mu \mathrm{M})$ was incubated with $\mathrm{A} \beta(100 \mu \mathrm{M})$ in the absence and presence of $\mathrm{CuCl}_{2}$ or $\mathrm{ZnCl}_{2}(100 \mu \mathrm{M})$ in $20 \mathrm{mM}$ ammonium acetate, $\mathrm{pH} 7.3$ at $37^{\circ} \mathrm{C}$ for $2 \mathrm{~h}$ without agitation. Before injection into the mass spectrometer, samples were diluted by 10 fold with $\mathrm{ddH}_{2} \mathrm{O}$. The capillary voltage, the drying gas flow, and the gas temperature were set to $58 \mathrm{kV}, 12 \mathrm{~L} / \mathrm{min}$, and $300{ }^{\circ} \mathrm{C}$, respectively. The fragment voltage was set to $170 \mathrm{~V}$.

2D ${ }^{1} \mathrm{H}-{ }^{15} \mathrm{~N}$ HSQC NMR spectroscopy. NMR samples were prepared as described in the previous study ${ }^{51}$. Uniformly ${ }^{15} \mathrm{~N}$-labeled $\mathrm{A} \beta_{40}$ (rPeptide Inc., Bogart, GA, USA) was initially dissolved in $\mathrm{NH}_{4} \mathrm{OH}(1 \% \mathrm{w} / \mathrm{w}$, aq; $10 \mu \mathrm{L})$. After lyophilizing the resulting solution, the peptide was stored at $-80{ }^{\circ} \mathrm{C}$. A solution of the ${ }^{15} \mathrm{~N}$-labeled $\mathrm{A} \beta_{40}$ monomer was prepared by dissolving the lyophilized peptide in the chilled $\mathrm{NaOH}$ solution $(10 \mathrm{mM})$ to make a stock concentration of ca. $200 \mu \mathrm{M}$. For $2 \mathrm{D}{ }^{1} \mathrm{H}-{ }^{15} \mathrm{~N}$ HSQC measurements, the stock solution was further diluted to be $40 \mu \mathrm{M}$ of ${ }^{15} \mathrm{~N}$-labeled $A \beta_{40}$ in the buffered solution [20 mM HEPES [4-(2-hydroxyethyl)-1-piperazineethanesulfonic acid], $\mathrm{pH}$ 7.4] containing $10 \% \mathrm{v} / \mathrm{v} \mathrm{D}_{2} \mathrm{O}$, and then treated with APP-C31 (200 $\left.\mu \mathrm{M}\right)$. All HSQC spectra were obtained at $5{ }^{\circ} \mathrm{C}$. Each spectrum was obtained from $256 t_{1}$ experiments using 64 transients and $1 \mathrm{~s}$ recycle delay. Data were processed by NMRPipe ${ }^{52}$ and analyzed by Sparky ${ }^{53}$. The assignment of backbone resonance was carried out based on the previously assigned information $^{51}$. CSP $\left(\Delta \delta \delta_{\mathrm{NH}}\right)$ was calculated by the equation below:

$$
\Delta \delta_{N H}=\sqrt{\Delta \delta_{H}{ }^{2}+\left(\frac{\Delta \delta_{N}}{6.5}\right)^{2}}
$$

where $\Delta \delta_{\mathrm{H}}$ and $\Delta \delta_{\mathrm{N}}$ represent the change of chemical shift in the proton and nitrogen dimensions, respectively.

ITC. All samples were dissolved in the buffered solution (20 mM HEPES, pH 7.4), and the resultant solutions were degassed for $3 \mathrm{~min}$ prior to the loading into the ITC instrument. To investigate the binding affinity of APP-C31 to A $\beta_{40}$, the final concentrations of APP-C31 (in the syringe) and $A \beta_{40}$ (in the cell) were adjusted to $600 \mu \mathrm{M}$ and $30 \mu \mathrm{M}$, respectively. To measure the 
binding affinity of metal ions to APP-C31, $2.1 \mathrm{mM}$ of $\mathrm{CuCl}_{2}$ or $\mathrm{ZnCl}_{2}$ (in the syringe) and $100 \mu \mathrm{M}$ of APP-C31 (in the cell) were used for experiments. Titration experiments composed of 28 injections were conducted. The injection volume was $2 \mu \mathrm{L}$ for the first injection to minimize effects of bubbles and $10 \mu \mathrm{L}$ for the remaining injections. To prevent $A \beta_{40}$ aggregation, the temperature and stirring speed were set to $10^{\circ} \mathrm{C}$ and $260 \mathrm{rpm}$, respectively. The initial delay was $1,800 \mathrm{~s}$ and the reference power was $10 \mu \mathrm{cal} / \mathrm{s}$. The heats of dilution of APP-C31, $\mathrm{CuCl}_{2}$, and $\mathrm{ZnCl}_{2}$ titrated into the same buffer were also examined. The ITC thermogram and binding isotherm were displayed after subtracting the dilution heat. The binding isotherms after baseline correction were fitted to the one set of sites binding model incorporated in the MicroCal Origin 7.0 software ${ }^{54}$.

Preparation of MD simulations. The atomistic NMR structure of $A \beta_{40}$ deposited in the protein data bank (PDB 2LFM ${ }^{28}$ ) was used as the initial conformation of A $\beta$ monomer. For APP-C31, the X-ray crystal structure of APP $666-693$ excised from the intracellular domain of APP complexed with Fe65 protein (PDB 3DXC ${ }^{29}$ ) was selected as the starting conformation of the protein. MD simulations of $A P P_{666-693}$ monomer, $A \beta_{40}$ monomer, and the $A P P_{666-693}-A \beta_{40}$ dimer were conducted by a GPU enabled Amber16 software suite ${ }^{20}$. Each monomer was immersed in an octahedral solvation box filled with TIP3P water molecules ${ }^{21}$. For the APP $666-693-A \beta_{40}$ dimer, 34 distinct dimeric conformations that were sampled from metadynamics MD simulations were used as the initial conformations (vide infra). The minimal distance from the protein surface to the solvation boundary was at least $12 \AA$. Monovalent counterions $\left(\mathrm{Na}^{+}\right.$or $\left.\mathrm{Cl}^{-}\right)$were added to ensure the charge neutrality of the simulated systems. To model the peptides, the ff14SB all atom amino acid force fields parameter set was adopted ${ }^{22}$. MD simulations were applied to 0.2 fs time integration steps in conjunction with the Settle algorithm that fixes the bond distance between a hydrogen atom and its heavy atom partner ${ }^{23}$. Particle Mesh Ewald (PME) method was employed to accelerate the calculations of long-range electrostatic interactions ${ }^{24}$. The simulations began by 4,000 steps of energy minimizations. The temperature of each solvated model was increased from $0 \mathrm{~K}$ to $100 \mathrm{~K}$ in 2 ns while restraining each carbon atom with a harmonic potential of spring constant as $2 \mathrm{kcal} / \mathrm{mol} / \AA^{2}$. The temperature was then increased from $100 \mathrm{~K}$ to $300 \mathrm{~K}$ in $10 \mathrm{~ns}$ while restraining each $\mathrm{C} \alpha$ atom with a harmonic potential of spring constant as $10 \mathrm{kcal} / \mathrm{mol} / \AA^{2}$. Prior to the production periods, additional $10 \mathrm{~ns}$ of equilibrations was performed while keeping the temperature at $300 \mathrm{~K}$ and the pressure at $1 \mathrm{~atm}$. The production runs lasted for $500 \mathrm{~ns}$ for the monomer and dimer models without any restraints to the solutes. 
Metadynamics MD simulations. Metadynamics MD simulations were employed to investigate the interfaces of the $A P_{666-693}-A \beta_{40}$ dimer. The COM distance of the two monomeric peptides, $A P P_{666-693}$ and $A \beta_{40}$, was used as the reaction coordinate of the dimerization. Gibbs free energy profile was computed along the chosen reaction coordinates without additional processing of the simulation data ${ }^{19}$. Using the metadynamics MD simulations, reversible association of the two monomers was monitored followed by achieving an enriched set of the associated dimer conformations. Metadynamics MD simulations were initiated from the last step of the constant temperature-pressure $M D$ simulations of the $A P P_{666-693}-A \beta_{40}$ dimer. To enhance the convergence of the simulations, the well-tempered metadynamics method was applied with the bias temperature of $500 \mathrm{~K}$ and the energy bin height of $0.005 \mathrm{kcal} / \mathrm{mol}^{25,26}$. The multi-walker method was used to diversify the dimer conformations ${ }^{27}$. Total 12 replicas of the dimers were simulated. Each replica was simulated for 700 ns resulting in $8.4 \mu$ s of gross simulation time. The COM distance was sampled from $5 \AA$ to $40 \AA$. The simulation temperature was held constant at $300 \mathrm{~K}$.

\section{Structural clustering of the dimer interfaces sampled from metadynamics MD simulations.} Upon completion of metadynamics MD simulations, structural cluster analysis was carried out to identify the distinct $A P P_{666-693}-A \beta_{40}$ dimer interfaces. First, the dimer interfaces that show the COM distances between $10 \AA$ to $15 \AA$ were collected, where the computed Gibbs free energy profile was minimized. Those collected interfaces were subject to the structural clustering analysis using VMD software. Two conformers having the backbone RMSD less than $3.0 \AA$ were considered to be similar structures, which resulted in 34 different structural clusters. A representative conformation of each structural cluster was subject to additional 500 ns MD simulations without structural constraints.

ThT fluorescence assay. The kinetics of $A \beta$ aggregation were detected by the ThT fluorescence assay. Samples containing A $\beta(25 \mu \mathrm{M})$ with or without APP-C31 $(25 \mu \mathrm{M})$ in $20 \mathrm{mM}$ HEPES, pH 7.4, $150 \mathrm{mM} \mathrm{NaCl}(40 \mu \mathrm{L})$ were incubated for $0 \mathrm{~h}, 0.3 \mathrm{~h}, 0.5 \mathrm{~h}, 0.7 \mathrm{~h}, 1 \mathrm{~h}, 1.3 \mathrm{~h}, 1.7 \mathrm{~h}, 2 \mathrm{~h}, 3 \mathrm{~h}$, $3.5 \mathrm{~h}, 4 \mathrm{~h}, 6 \mathrm{~h}$, and $8 \mathrm{~h}$ (under metal-free $A \beta_{40}$ conditions), for $0 \mathrm{~h}, 0.25 \mathrm{~h}, 0.5 \mathrm{~h}, 0.75 \mathrm{~h}, 1 \mathrm{~h}, 1.25$ $\mathrm{h}, 1.5 \mathrm{~h}, 2 \mathrm{~h}, 2.5 \mathrm{~h}, 4 \mathrm{~h}$, and $8 \mathrm{~h}$ (under metal-free $A \beta_{42}$ conditions), and for $0 \mathrm{~h}, 1 \mathrm{~h}, 2 \mathrm{~h}, 4 \mathrm{~h}, 8 \mathrm{~h}$, $24 \mathrm{~h}, 48 \mathrm{~h}$, and $72 \mathrm{~h}$ (under $\mathrm{Cu}(\mathrm{II})$ - or $\mathrm{Zn}(\mathrm{II})$-present conditions) at $37^{\circ} \mathrm{C}$ with constant agitation. Upon 20 min treatment of ThT into each sample, the fluorescence intensity was measured with excitation at $440 \mathrm{~nm}$ and emission at $490 \mathrm{~nm}$. 
Dot blot assay. Samples containing $A \beta(100 \mu \mathrm{M})$ with and without APP-C31 $(100 \mu \mathrm{M})$ in the absence and presence of $\mathrm{CuCl}_{2}$ or $\mathrm{ZnCl}_{2}(100 \mu \mathrm{M})$ were incubated in $20 \mathrm{mM}$ HEPES, pH 7.4, 150 $\mathrm{mM} \mathrm{NaCl}$ at $37^{\circ} \mathrm{C}$ with constant agitation. After $0 \mathrm{~h}, 1 \mathrm{~h}, 2 \mathrm{~h}, 4 \mathrm{~h}$, and $8 \mathrm{~h}$ incubation (under metalfree conditions) or $0 \mathrm{~h}, 1 \mathrm{~h}, 2 \mathrm{~h}, 4 \mathrm{~h}, 8 \mathrm{~h}$, and $24 \mathrm{~h}$ incubation (under Cu(II)- or Zn(II)-added conditions), the samples $(4 \mu \mathrm{L})$ were spotted on a nitrocellulose membrane. The membrane was blocked with bovine serum albumin (BSA; 3\% w/v; Biosesang, Seongnam, Republic of Korea) in Tris-buffered saline (TBS) containing $0.01 \% \mathrm{v} / \mathrm{v}$ Tween-20 (TBS-T) for $1.5 \mathrm{~h}$ at room temperature. Then, the membrane was incubated with a primary antibody [an anti-oligomer antibody (A11; 1:2,500, Invitrogen, Carlsbad, CA, USA), an anti-A $\beta$ antibody (6E10; 1:2,000, Covance, Princeton, NJ, USA), or an anti-APP antibody (Y188; 1:2,000, Abcam, Cambridge, MA, USA)] for $1.5 \mathrm{~h}$ at room temperature. After washing with TBS-T three times (7 min each), the horseradish peroxidase-conjugated goat anti-mouse secondary antibody (1:2,500 for 6E10; Cayman, Ann Arbor, MI, USA) or the goat anti-rabbit secondary antibody (1:2,000 for A11 and an Y188 antibody; Promega, Madison, WI, USA) in the solution of BSA ( $2 \% \mathrm{w} / \mathrm{v}$ in TBS-T) was added to the membrane and incubated for $1 \mathrm{~h}$ at room temperature. The membrane was visualized by an imaging system with a homemade ECL kit ${ }^{55}$. To monitor both peptides in the samples, the same membrane was stripped after the visualization by treating it with hydrogen peroxide $\left(\mathrm{H}_{2} \mathrm{O}_{2}\right)$ for 30 min at room temperature followed by washing four times with TBS-T for 10 min each, blocking with the solution of BSA [3\% w/v in TBS-T $(0.01 \% \mathrm{v} / \mathrm{v})]$, and incubating with the other antibody.

CD spectroscopy. APP-C31 (100 $\mu \mathrm{M})$ was incubated in $20 \mathrm{mM}$ HEPES, pH 7.4, $150 \mathrm{mM} \mathrm{NaF}$ for 0 and $24 \mathrm{~h}$. The CD spectra of APP-C31 samples were collected in the range from 190 to 250 $\mathrm{nm}$ with a cell path length of $0.5 \mathrm{~mm}$. The digital integration time, the bandwidth, and the scanning speed were $4 \mathrm{~s}, 2 \mathrm{~nm}$, and $20 \mathrm{~nm} / \mathrm{min}$, respectively. Each spectrum was smoothed by Fourier transforms. The secondary structure of APP-C31 was analyzed following the previously reported method $^{56}$.

TEM. Samples for TEM measurements were prepared based on previously published methods ${ }^{34}$. Glow-discharged grids (Formvar/Carbon 300-mesh, Electron Microscopy Sciences, Hatfield, PA, USA) were treated with the resultant samples for $2 \mathrm{~min}$ at room temperature. Excess sample was removed using a filter paper. Each grid was washed three times with $\mathrm{ddH}_{2} \mathrm{O}$ and incubated with uranyl acetate $\left(1 \% \mathrm{w} / \mathrm{v} d \mathrm{dH}_{2} \mathrm{O} ; 5 \mu \mathrm{L}\right)$ for $1 \mathrm{~min}$. After removing excess uranyl acetate, the grids were dried for at least $20 \mathrm{~min}$ at room temperature. Images of each grid were taken at $200 \mathrm{kV}$ with a magnification of $9,900 x$ or $29,000 x$. 
Cell culture and microinjection. The human neuroblastoma SH-SY5Y cell line was purchased from the American Type Culture Collection (ATCC; Manassas, VA, USA). The cell line was maintained in media containing 50\% v/v Dulbecco's Modified Eagle Medium and 50\% v/v Nutrient Mixture F12 (phenol red-free DMEM/F12; GIBCO, Grand Island, NY, USA) supplemented with $10 \% \mathrm{v} / \mathrm{v}$ fetal bovine serum (GIBCO) and $100 \mathrm{U} / \mathrm{mL}$ penicillin-streptomycin (GIBCO). Cells were grown and maintained at $37{ }^{\circ} \mathrm{C}$ in a humidified atmosphere with $5 \% \mathrm{CO}_{2}$. The cells used for our studies did not indicate mycoplasma contamination. Cells were plated on an imaging dish ( $35 \mathrm{~mm}$; $1.0 \times 10^{5}$ cells per $1 \mathrm{~mL}$ ) and incubated for $48 \mathrm{~h}$ before microinjection. The solutions of peptides were centrifuged at 5,000 rpm for $1 \mathrm{~min}$ to remove large aggregates that can clog a microinjection glass capillary. The solutions of either $\mathrm{A} \beta_{40}(10 \mu \mathrm{M})$, APP-C31 $(10 \mu \mathrm{M})$, or both peptides in the absence and presence of $\mathrm{CuCl}_{2}$ or $\mathrm{ZnCl}_{2}(10 \mu \mathrm{M})$ were mixed with dextran labeled with Texas Red (0.4 mg/mL, 3,000 MW; Invitrogen, Carlsbad, CA, USA) followed by injection into the cells using an InjectMan 4 micromanipulator and a Femtojet $4 \mathrm{i}$ microinjector. The injection pressure $\left(P_{\mathrm{i}}\right)$, the compensation pressure $\left(P_{\mathrm{c}}\right)$, and the injection time $\left(t_{\mathrm{i}}\right)$ were set to $50 \mathrm{hPa}, 20 \mathrm{hPa}$, and $0.2 \mathrm{~s}$, respectively. Cell viability was determined based on the previously reported procedures ${ }^{42}$. After microinjection, the number of Texas Red-positive cells was first counted after $3 \mathrm{~h}$ and it was assigned as $100 \%$ of cell viability to exclude the cells damaged by microinjection. Cells were counted after $24 \mathrm{~h}$ incubation and cell viability (\%) was calculated. At least 100 cells from each sample were injected and analyzed. Experiments were performed at least triplicate. Data were represented as mean \pm standard error of the mean (s.e.m). Fluorescence analysis of the cells was conducted by a fluorescence microscope with a RFP light cube [excitation at $531( \pm 40) \mathrm{nm}$ and emission at $593( \pm 40) \mathrm{nm}]$.

Annexin V staining. SH-SY5Y cells were plated on an imaging dish $\left(35 \mathrm{~mm} ; 0.3 \times 10^{5}\right.$ cells per $1 \mathrm{~mL})$ and incubated for $48 \mathrm{~h}$. The solutions of either $\mathrm{A} \beta_{40}(10 \mu \mathrm{M})$, APP-C31 $(10 \mu \mathrm{M})$, or both peptides were mixed with dextran labeled with Texas Red, and the resultant solutions were microinjected into the cells, as described above. After $24 \mathrm{~h}$ incubation, the cells were washed with annexin-binding buffer and stained with annexin V-Alexa Fluor 488 for detecting apoptosis following the manufacturer's instruction (FITC Annexin V/Dead Cell Apoptosis Kit; V13241, Invitrogen, Carlsbad, CA, USA). Fluorescent responses of annexin $\mathrm{V}$ and Texas Red-labeled dextran were identified by a fluorescence microscope with an GFP light cube [excitation at 470 ( \pm 22) $\mathrm{nm}$ and emission at $525( \pm 50) \mathrm{nm}$ ] and a Cy5 light cube [excitation at $628( \pm 40) \mathrm{nm}$ and emission at $685( \pm 40) \mathrm{nm}$ ], respectively. Pearson's correlation coefficient for the indication of co- 
localization was calculated with Coloc2 plugin in Fiji software ${ }^{57}$.

Confocal microscopy. All experiments were conducted with ${ }^{H F 647} A \beta_{40}$ (Anaspec). The concentration of ${ }^{\mathrm{HF} 647} \mathrm{~A} \beta_{40}$ was determined by measuring the absorbance at $649 \mathrm{~nm}\left(\varepsilon_{649}=\right.$ $\left.250,000 \mathrm{M}^{-1} \mathrm{~cm}^{-1}\right)^{45}$. ${ }^{\mathrm{HF} 647} \mathrm{~A} \beta_{40}(10 \mu \mathrm{M})$ with or without APP-C31 $(10 \mu \mathrm{M})$ was microinjected into SH-SY5Y cells followed by incubation for $24 \mathrm{~h}$. Images were obtained by adopting a Zeiss LSM 880 confocal microscope with a lateral resolution of $120 \mathrm{~nm}$ (excitation at $633 \mathrm{~nm}$ ). ${ }^{\mathrm{HF} 647} \mathrm{~A} \beta_{40}$ aggregates were monitored from three or more cells. The size of ${ }^{\mathrm{HF} 647} \mathrm{~A} \beta_{40}$ aggregates was determined by the "analyze particles" program of Fiji software based on the previously reported reports $^{46}$. All pixels above the threshold value were selected to calculate the area of ${ }^{H F 647} A \beta_{40}$ aggregates. Our analysis included ${ }^{\mathrm{HF} 647} \mathrm{~A} \beta_{40}$ aggregates with the size larger than $0.05 \mu \mathrm{m}^{2}$.

Neuronal differentiation from embryonic stem cells. Human neurons were differentiated from neural progenitor cells (NPCs), which are derived from human embryonic stem cells (hESCs), WA09 (also known as H9). hESCs were maintained on inactivated mouse embryonic fibroblasts (MEFs) in hESC-media comprising DMEM/F12 (GIBCO) with MEM non-essential amino acids (MEM NEAA; GIBCO), sodium bicarbonate (14 mM; Sigma-Aldrich), L-glutamine (1 mM; SigmaAldrich), $\beta$-mercaptoethanol (100 $\mu \mathrm{M}$; Merck Millipore, Billerica, MA, USA), knockout serum replacement (20\% v/v; GIBCO), and bFGF (10 ng/mL; R\&D systems, McKinley Place, MN, USA). MEFs were collected from E13.5 CrljOri:CD1 (ICR) mice (Orientbio, Seongnam, Republic of Korea) and inactivated with $10 \mu \mathrm{g} / \mathrm{mL}$ of mitomycin C (AG Scientific, San Diego, CA, USA) in $2 \mathrm{~h}$. hESC colonies were dissociated with Collagenase IV and plated onto Petri dishes in hESC-media to form embryoid bodies (EBs). At the following day, floating EBs were treated with LDN (Selleckchem, Huston, TX, USA) and SB-431542 (Cayman) in DMEM/F12+glutamax (GIBCO) with N2 and B27 supplements (GIBCO). The treatment was continued for a week, followed by plating onto growth factor reduced matrigel (BD biosciences)-coated dishes in DMEM/F12+glutamax (GIBCO) with N2 and B27 supplements (N2/B27 media) and laminin (1 $\mathrm{mg} / \mathrm{mL}$; GIBCO). Within a few days, neural rosettes were manually picked and dissociated with Accutase (Innovative Cell Technologies, San Diego, CA, USA) and plated onto poly-Lornithine/laminin-coated dishes with NPC media (N2/B27 media with $20 \mathrm{ng} / \mathrm{mL}$ of bFGF). To differentiate NPCs into neurons, NPCs were plated onto poly-L-ornithine/laminin-coated dishes in N2/B27 media in the presence of ascorbic acid (200 nM; Sigma-Aldrich), dcAMP (500 mg/mL; Selleckchem), BDNF (20 ng/mL; Peprotech, London, UK), GDNF (20 ng/mL; Peprotech), and 
laminin $(1 \mathrm{mg} / \mathrm{mL})$, as previously described ${ }^{58}$. Protocols describing the use of MEFs and $\mathrm{hESCs}$ were approved by the ethical requirements and regulations of the Institutional Review Board of KAIST (IRB \#KA2020-37 for MEFs and IRB \#KA2018-61 for hESCs).

Measurement of neurite outgrowth. Human NPCs were differentiated into neurons for $2 \mathrm{~d}$ and the media was replaced by fresh media. Neurons were treated with either A $(20 \mu \mathrm{M})$, APP-C31 $(20 \mu \mathrm{M})$, or both peptides followed by incubation for $24 \mathrm{~h}$ and $72 \mathrm{~h}$. Under each condition, at least 5 randomly selected fields were captured with an Olympus IX71 microscope. The neurite of a neuron measured from the soma to the tip was analyzed using NeuronJ in Fiji software ${ }^{59}$.

\section{Acknowledgments}

This research is supported by the National Research Foundation of Korea (NRF) grants funded by the Korean government [NRF-2017R1A2B3002585 (M.H.L.); NRF-2019R1A2C1004954 and NRF-2018K1A3A1A39088040 (Y.-H.L.); NRF-2019R1C1C1010482 (J.H.; Jinju Han)]; the Institute for Basic Science (IBS-R010-A1) in Korea (M.-H.B.); the Basic Science Research Program through the NRF funded by the Ministry of Education (NRF-2019R1A6A1A10073887) (M.H.L.); the Venture Research Program for Graduate and PhD students by KAIST (N11180157) (H.D.). J.H. (Jiyeon Han) and H.D. thank the Global Ph.D. fellowship program for support through the NRF funded by the Ministry of Education [NRF-2019H1A2A1073754 (J.H.) and NRF2018H1A2A1059772 (H.D.)].

Competing financial interests. The authors declare no competing financial interests.

\section{References}

1. Müller, U. C., Deller, T. \& Korte, M. Not just amyloid: physiological functions of the amyloid precursor protein family. Nat. Rev. Neurosci. 18, 281-298 (2017).

2. LaFerla, F. M., Green, K. N. \& Oddo, S. Intracellular amyloid- $\beta$ in Alzheimer's disease. Nat. Rev. Neurosci. 8, 499-509 (2007).

3. Savelieff, M. G. et al. Development of multifunctional molecules as potential therapeutic candidates for Alzheimer's disease, Parkinson's disease, and amyotrophic lateral sclerosis in the last decade. Chem. Rev. 119, 1221-1322 (2019).

4. Lee, S. J. C., Nam, E., Lee, H. J., Savelieff, M. G. \& Lim, M. H. Towards an understanding of amyloid- $\beta$ oligomers: characterization, toxicity mechanisms, and inhibitors. Chem. Soc. Rev. 46, 310-323 (2017). 
5. Billings, L. M., Oddo, S., Green, K. N., McGaugh, J. L. \& LaFerla, F. M. Intraneuronal A $\beta$ causes the onset of early Alzheimer's disease-related cognitive deficits in transgenic mice. Neuron 45, 675-688 (2005).

6. Gervais, F. G. et al. Involvement of caspases in proteolytic cleavage of Alzheimer's amyloid$\beta$ precursor protein and amyloidogenic $A \beta$ peptide formation. Cell 97, 395-406 (1999).

7. Lu, D. C. et al. A second cytotoxic proteolytic peptide derived from amyloid $\beta$-protein precursor. Nat. Med. 6, 397-404 (2000).

8. Zhao, M., Su, J., Head, E. \& Cotman, C. W. Accumulation of caspase cleaved amyloid precursor protein represents an early neurodegenerative event in aging and in Alzheimer's disease. Neurobiol. Dis. 14, 391-403 (2003).

9. McPhie, D. L. et al. $\beta$-Secretase cleavage of the amyloid precursor protein mediates neuronal apoptosis caused by familial Alzheimer's disease mutations. Mol. Brain Res. 97, 103-113 (2001).

10. Trillaud-Doppia, E., Paradis-Isler, N. \& Boehm, J. A single amino acid difference between the intracellular domains of amyloid precursor protein and amyloid-like precursor protein 2 enables induction of synaptic depression and block of long-term potentiation. Neurobiol. Dis. 91, 94-104 (2016).

11. Park, G. et al. Caspase activation and caspase-mediated cleavage of APP is associated with amyloid $\beta$-protein-induced synapse loss in Alzheimer's disease. Cell Rep. 31, 107839 (2020).

12. Galvan, V. et al. Reversal of Alzheimer's-like pathology and behavior in human APP transgenic mice by mutation of Asp664. Proc. Natl. Acad. Sci. U. S. A. 103, 7130-7135 (2006).

13. Lu, D. C., Shaked, G. M., Masliah, E., Bredesen, D. E. \& Koo, E. H. Amyloid $\beta$ protein toxicity mediated by the formation of amyloid- $\beta$ protein precursor complexes. Ann. Neurol. 54, 781789 (2003).

14. Pensalfini, A. et al. Intracellular amyloid and the neuronal origin of Alzheimer neuritic plaques. Neurobiol. Dis. 71, 53-61 (2014).

15. Langui, D. et al. Subcellular topography of neuronal Abeta peptide in APPxPS1 transgenic mice. Am. J. Pathol. 165, 1465-1477 (2004).

16. Heck, A. J. \& Van Den Heuvel, R. H. Investigation of intact protein complexes by mass spectrometry. Mass Spectrom. Rev. 23, 368-389 (2004).

17. Perkins, J. R., Diboun, I., Dessailly, B. H., Lees, J. G. \& Orengo, C. Transient protein-protein interactions: structural, functional, and network properties. Structure 18, 1233-1243 (2010). 
18. Ryu, H. et al. Pitfalls in computational modeling of chemical reactions and how to avoid them. Organometallics 37, 3228-3239 (2018).

19. Cavalli, A., Spitaleri, A., Saladino, G. \& Gervasio, F. L. Investigating drug-target association and dissociation mechanisms using metadynamics-based algorithms. Acc. Chem. Res. 48, 277-285 (2015).

20. Case, D. A. et al. The amber biomolecular simulation programs. J. Comput. Chem. 26, 1668-1688 (2005).

21. Jorgensen, W. L., Chandrasekhar, J., Madura, J. D., Impey, R. W. \& Klein, M. L. Comparison of simple potential functions for simulating liquid water. J. Chem. Phys. 79, 926-935 (1983).

22. Maier, J. A. et al. ff14SB: improving the accuracy of protein side chain and backbone parameters from ff99SB. J. Chem. Theory Comput. 11, 3696-3713 (2015).

23. Miyamoto, S. \& Kollman, P. A. Settle: an analytical version of the SHAKE and RATTLE algorithm for rigid water models. J. Comput. Chem. 13, 952-962 (1992).

24. Darden, T., York, D. \& Pedersen, L. Particle mesh Ewald: an $N \cdot \log (N)$ method for Ewald sums in large systems. J. Chem. Phys. 98, 10089-10092 (1993).

25. Barducci, A., Bussi, G. \& Parrinello, M. Well-tempered metadynamics: A smoothly converging and tunable free-energy method. Phys. Rev. Lett. 100, 020603 (2008).

26. Bonomi, M. \& Parrinello, M. Enhanced sampling in the well-tempered ensemble. Phys. Rev. Lett. 104, 190601 (2010).

27. Raiteri, P., Laio, A., Gervasio, F. L., Micheletti, C. \& Parrinello, M. Efficient reconstruction of complex free energy landscapes by multiple walkers metadynamics. J. Phys. Chem. B 110, 3533-3539 (2006).

28. Vivekanandan, S., Brender, J. R., Lee, S. Y. \& Ramamoorthy, A. A partially folded structure of amyloid-beta(1-40) in an aqueous environment. Biochem. Biophys. Res. Commun. 411, 312-316 (2011).

29. Radzimanowski, J. et al. Structure of the intracellular domain of the amyloid precursor protein in complex with Fe65-PTB2. EMBO Rep. 9, 1134-1140 (2008).

30. Caballero, D. et al. Intrinsic $\alpha$-helical and $\beta$-sheet conformational preferences: a computational case study of alanine. Protein Sci. 23, 970-980 (2014).

31. Zhou, R., Huang, X., Margulis, C. J. \& Berne, B. J. Hydrophobic collapse in multidomain protein folding. Science 305, 1605-1609 (2004).

32. Choi, T. S., Lee, H. J., Han, J. Y., Lim, M. H. \& Kim, H. I. Molecular insights into human serum albumin as a receptor of amyloid- $\beta$ in the extracellular region. J. Am. Chem. Soc. 
139, 15437-15445 (2017).

33. Kayed, R. et al. Common structure of soluble amyloid oligomers implies common mechanism of pathogenesis. Science 300, 486-489 (2003).

34. Beck, M. W. et al. Structure-mechanism-based engineering of chemical regulators targeting distinct pathological factors in Alzheimer's disease. Nat. Commun. 7, 13115 (2016).

35. Sun, J. et al. CRISPR/Cas9 editing of APP C-terminus attenuates $\beta$-cleavage and promotes $\alpha$-cleavage. Nat. Commun. 10, 53 (2019).

36. Faller, P., Hureau, C. \& Berthoumieu, O. Role of metal ions in the self-assembly of the Alzheimer's amyloid- $\beta$ peptide. Inorg. Chem. 52, 12193-206 (2013).

37. Minniti, A. N. et al. Intracellular amyloid formation in muscle cells of Abeta-transgenic Caenorhabditis elegans: determinants and physiological role in copper detoxification. Mol. Neurodegener. 4, 2 (2009).

38. Seo, B. R., Lee, S. J., Cho, K. S., Yoon, Y. H. \& Koh, J. Y. The zinc ionophore clioquinol reverses autophagy arrest in chloroquine-treated ARPE-19 cells and in APP/mutant presenilin-1-transfected Chinese hamster ovary cells. Neurobiol. Aging 36, 3228-3238 (2015).

39. Tadrowski, S. et al. Metal ions play an essential catalytic role in the mechanism of ketolacid reductoisomerase. Chem. Eur. J. 22, 7427-7436 (2016).

40. Karlsen, V., Heggset, E. B. \& Sørlie, M. The use of isothermal titration calorimetry to determine the thermodynamics of metal ion binding to low-cost sorbents. Thermochim. Acta 501, 119-121 (2010).

41. Zhang, Y., McLaughlin, R., Goodyer, C. \& LeBlanc, A. Selective cytotoxicity of intracellular amyloid beta peptide1-42 through p53 and Bax in cultured primary human neurons. J. Cell. Biol. 156, 519-529 (2002).

42. Nagai, Y. et al. A toxic monomeric conformer of the polyglutamine protein. Nat. Struct. Mol. Biol. 14, 332-340 (2007).

43. Umeda, T. et al. Intraneuronal amyloid $\beta$ oligomers cause cell death via endoplasmic reticulum stress, endosomal/lysosomal leakage, and mitochondrial dysfunction in vivo. J. Neurosci. Res. 89, 1031-1042 (2011).

44. Dunn, K. W., Kamocka, M. M. \& McDonald, J. H. A practical guide to evaluating colocalization in biological microscopy. Am. J. Physiol. Cell Physiol. 300, C723-C742 (2011).

45. Esbjörner, E. K. et al. Direct observations of amyloid $\beta$ self-assembly in live cells provide insights into differences in the kinetics of $A \beta(1-40)$ and $A \beta(1-42)$ aggregation. Chem. Biol. 21, 732-742 (2014). 
46. Tokuraku, K., Marquardt, M. \& Ikezu, T. Real-time imaging and quantification of amyloid- $\beta$ peptide aggregates by novel quantum-dot nanoprobes. PLOS ONE 4, e8492 (2010).

47. Bruce, J. I. E., Giovannucci, D. R., Blinder, G., Shuttleworth, T. J. \& Yule, D. I. Modulation of [Ca2+]i signaling dynamics and metabolism by perinuclear mitochondria in mouse parotid acinar cells. J. Biol. Chem. 279, 12909-12917 (2004).

48. Nirmalraj, P. N. et al. Complete aggregation pathway of amyloid $\beta$ (1-40) and (1-42) resolved on an atomically clean interface. Sci. Adv. 6, eaaz6014 (2020).

49. Woulfe, J. Nuclear bodies in neurodegenerative disease. Biochim. Biophys. Acta Mol. Cell. Res. 1783, 2195-2206 (2008).

50. Kim, H. -S. et al. C-terminal fragments of amyloid precursor protein exert neurotoxicity by inducing glycogen synthase kinase-3 $\beta$ expression. FASEB J. 17, 1-28 (2003).

51. Hyung, S. J. et al. Insights into antiamyloidogenic properties of the green tea extract (-)epigallocatechin-3-gallate toward metal-associated amyloid- $\beta$ species. Proc. Natl. Acad. Sci. U. S. A. 110, 3743-3748 (2013).

52. Delaglio, F. et al. NMRPipe: a multidimensional spectral processing system based on UNIX pipes. J Biomol. NMR 6, 277-293 (1995).

53. Sparky 3, https://www.cgl.ucsf.edu/home/sparky/, (accessed December 2020).

54. Kim, J. Y. et al. Non-covalent forces tune the electron transfer complex between ferredoxin and sulfite reductase to optimize enzymatic activity. Biochem. J. 473, 3837-3854 (2016).

55. Mruk, D. D. \& Cheng, C. Y. Enhanced chemiluminescence (ECL) for routine immunoblotting: an inexpensive alternative to commercially available kits. Spermatogenesis 1, 121-122 (2011).

56. Micsonai, A. et al. Accurate secondary structure prediction and fold recognition for circular dichroism spectroscopy. Proc. Natl. Aca. Sci. U. S. A. 112, E3095-E3103 (2015).

57. Moser, B., Hochreiter, B., Herbst, R. \& Schmid, J. A. Fluorescence colocalization microscopy analysis can be improved by combining object-recognition with pixel-intensitycorrelation. Biotechnol. J. 12, 1600332 (2017).

58. Brennand, K. J. et al. Modelling schizophrenia using human induced pluripotent stem cells. Nature 473, 221-225 (2011).

59. Popko, J., Fernandes, A., Brites, D. \& Lanier, L. M. Automated analysis of NeuronJ tracing data. Cytometry A 75, 371-376 (2009). 